\title{
Lifting removal of cationic dye (methylene blue) from wastewater by improving Zr-MOFs via second metal Al coordination
}

\author{
Naser Al Amery ${ }^{1, *}$, Hussein Rasool Abid ${ }^{1,2,3}$, Shaobin Wang ${ }^{4}$ (i) and Shaomin Liu ${ }^{1}$ (]) \\ ${ }^{1}$ Chemical Engineering, WA School of Mines: Minerals, Energy and Chemical Engineering, Curtin University, Australia \\ ${ }^{2}$ Environmental Department, Applied Medical Science, University of Karbala, Iraq \\ ${ }^{3}$ School of Engineering, Edith Cowan University, Australia \\ ${ }^{4}$ School of Chemical Engineering, University of Adelaide, Australia
}

\begin{abstract}
Metal organic frameworks (MOFs) are frequently used as adsorbents in adsorption processes to remove dyes from effluent produced by the textile industry. Today, dye contaminants have become an important environmental problem. One of these dyes is methylene blue (MB) and its removal from wastewater is a priority because it is persistent and non degradable. $\mathrm{MB}$ is used in many industries although it has potential harmful effects on human and aquatic life and can be considered a hazardous chemical when in wastewater. The present study shows the potential applications for enhanced forms of UiO-66 MOFs, such as UiO-66, UiO-66-10\%Al and UiO-66-30\%Al. These forms were prepared to remove $\mathrm{MB}$ from wastewater using batch experiments. Characterisation of adsorbents were accomplished successfully using Fourier transform infrared, X-ray powder diffraction, Brunauer-Emmett-Teller surface area and thermogravimetric analysis techniques. To investigate equilibrium adsorptive behaviour, Langmuir and Freundlich isotherm models were tested against the experimental data. Based on linear regression correlation coefficient $\left(\mathrm{R}^{2}\right)$, the Freundlich model described the equilibrium isotherm of $\mathrm{MOF} / \mathrm{MB}$ better than the Langmuir model. Of all forms of UiO-66 MOF, UiO-66-10\%Al had the maximum Langmuir adsorption capacity at $49.26 \mathrm{mg} / \mathrm{g}$. A kinetics study examined pseudo first-order, pseudo second order and Elovich models to determine which could explain the sorption mechanism. While the pseudo second order and Elovich models showed a good fit with the experimental data, the correlation coefficient of the pseudo second-order model was the highest. These results indicate that adsorption of $\mathrm{MB}$ is controlled by a chemisorption mechanism. Further, intraparticle diffusion was utilised to describe the adsorption mechanism and determine the rate-limiting steps in the adsorption process.
\end{abstract}

Key words: Metal Organic Frameworks (MOFs), dye, methylene blue, pollutants removal, adsorption

\section{INTRODUCTION}

Despite government regulations, ensuring environmental compliance with established terms of wastewater release and chemical handling is difficult [1]. Today, dye contaminants have become one of the most important environmental problems in the world. Effluent with organic dyes discarded into natural watercourses endanger living creatures and the environment because of their toxicity and carcinogenic effects [2]. In addition, dye content in water prevents sunlight penetration which decreases plant photosynthesis [1].

Significant amounts of dyes are employed in a wide range of industries involved in producing paper, textile, leather, pharmaceutics, food, cosmetics, print products, iron-steel products, coke, petroleum, pesticides, paints, solvents, wood-preserving chemicals. Further, their manufacturing plants consume large volumes of water that in turn generate large volumes of wastewater [3]. Almost 100,000 dyes and pigments have been tabulated to exist, consisting of 7000 kinds of chemical structures, that are used to produce $7 \times 10^{5}$ tonnes per year worldwide [4-8]. The majority of these dyes are resistant to biodegradation and oxidation processes [9]. About $10-15 \%$ of the dyes is discharged into the effluent during the dyeing process $[10$, 11]. Recently, studies have reported that around $12 \%$ of synthetic dyes are wasted through colouring processes and operations $[12] ; 20 \%$ of lost dyes enter industrial wastewaters $[13,14]$.

Dyes can be divided into two main groups, anionic (acidic) and cationic (basic) colour dyes. Methylene blue $(\mathrm{MB})$ is a basic dye that is a focus of this study. Although $\mathrm{MB}$ is used in some medical applications, it is also widely used in colouring paper, dyed cottons, wools, coating for paper stocks, etc. Though MB is not strongly hazardous, it has some harmful effects. Acute exposure to $\mathrm{MB}$ will cause increased heart rate, vomiting, shock, Heinz body formation, cyanosis, jaundice, quadriplegia and tissue necrosis in humans [15].

$\begin{array}{ll}\text { Received } & \text { : February 08, 2021 } \\ \text { Revised } & \text { : March 18, 2021 } \\ \text { Accepted } & \text { : June 17, 2021 }\end{array}$


Environmentally, it is essential to remove dyes from industrial wastewater because of their toxicity and high visibility [7, 16-18]. Consequently, there is a continuous urgent need to ensure the removal these pollutants from industrial effluent and to comply with government legislation [19]. Many techniques have been attempted to discolour industrial discharge that involve chemical, biological and physical removal methods; however, most are unsuccessful because of their limitations and disadvantages [20].

Adsorption is a well-known and favourite technique because of its feasibility, simplicity and efficiency in the removal of such contaminants [21]. Many adsorbents have been employed to treat industrial wastewater containing dye. They include activated carbon derived from different sources of raw materials [22-33], agricultural solid waste [34 $-47]$, biosorbents $[17,18,48-60]$, zeolites [61-66], industrial solid wastes $[15,67-74]$, natural clay minerals [75-83], resins [84-87], metal oxides [88, 89], metal organic frameworks (MOFs) [2, 90-93].

Activated carbon from various sources has been the most investigated adsorbent in laboratories and most used by industries to remove basic dyes from their wastewaters $[87,94-97]$. However, its cost has limited its commercial use as a sorbent. As a result, many studies have been undertaken in the last decade to identify a cost-effective sorbent [98].

MOF [99-106], or hybrid inorganic and organic framework [107], is a 21st century material with tuneable options, organic functionality, open metal sites in its skeleton, large-sized pores, high surface areas (1000 to $10,000 \mathrm{~m}^{2} / \mathrm{g}$ ) as well as high thermal, water, chemical, architectural and mechanical stability $[2,108]$. It is a class of ultra-high porous material constructed with secondary building units (SBUs)[109] and synthesised by reticular chemistry $[110,111]$ that connect the inorganic part with the metal ion to the organic part with polytopic carboxylate group to form vertices and linkers with strong bonds [112]. The variety of geometry, size and functionality of the constituents of MOFs has enabled scientists around the world to synthesise more than 84,185 MOF structures [102]. Their variety and multiplicity, as well as permanent porosity, make them favourable materials in many applications, such as $\mathrm{CO}_{2}$ capture, hydrogen and methane storage, sensors, photocatalysis, drug delivery, catalysis applications and the adsorptive removal of contaminants from aqueous solutions [90, 112-117].

The objective of the present study is to describe the synthesis and characterisation of single-metal Zr-MOF (UiO -66) and bimetal Zr-MOFs (UiO-66-10\%Al and UiO-66$30 \% \mathrm{Al}$ ), and examine their potential as sorbents to remove $\mathrm{MB}$, a cationic basic dye, in wastewater. The kinetics and equilibrium of the adsorption process were fitted to kinetics models and equilibrium theoretical models. Further, the mechanism that limits the rate of sorption reaction was investigated using an intraparticle diffusion method to improve understanding of the dynamics in the adsorption process.

\section{METHODOLOGY}

\subsection{Synthesis and activation}

All chemicals were supplied by Sigma-Aldrich (Australia) without further purifications.

A scaled-up procedure of a previously reported method [59] of synthesising Zr-MOF was successfully undertaken, using a modified ratio of $\mathrm{ZrCl}_{4}$ :BDC:DMF $(2.27 \mathrm{mmol}$ $\mathrm{ZrCl}_{4}, 2.27 \mathrm{mmol}$ 1,4-benzenedicarboxylic acid [BDC]). The abovementioned chemicals were mixed with continuous agitation with $405.38 \mathrm{mmol} \mathrm{N}, \quad \mathrm{N}$-dimethylformamide (DMF) solvothermally. The resulting mixture was placed in an autoclave at $393 \mathrm{~K}$ for $1 \mathrm{~d}$. The product Zr-MOF was filtered, dried and immersed in chloroform for $5 \mathrm{~d}$. After activation by chloroform was completed, the solid was filtered and dried using vacuum and heated at $463 \mathrm{~K}$ for $48 \mathrm{~h}$.

The following method was used to synthesise UiO-6610\%Al. Terephthalic acid (1.1 g, 98\%; Sigma-Aldrich) and DMF (73 mL, 99\%; Sigma-Aldrich) were mixed together and stirred until the acid dissolved. Within $10 \mathrm{~min}$ of the clear solution forming, $\mathrm{ZrCl} 4$ (1.5 g; Sigma-Aldrich, 99\%) was added to the solution with continued stirring for another $5 \mathrm{~min} . \mathrm{Al}\left(\mathrm{NO}_{3}\right)_{3} .9 \mathrm{H}_{2} \mathrm{O}(0.15 \mathrm{~g})$ was then added, along with $2 \mathrm{~mL}$ of $\mathrm{H}_{2} \mathrm{O}$, to the mixture and stirred for another $15 \mathrm{~min}$. The solution was transferred to a $125-\mathrm{mL}$ Teflon-lined autoclave, which was tightly sealed and then placed in a preheated oven at $132{ }^{\circ} \mathrm{C}$ for $24 \mathrm{~h}$. The white powder product of $\mathrm{UiO}-66-10 \% \mathrm{Al}$ was collected using a centrifuge machine and washed in DMF three times. The resultant product was dried in an oven and activated by immersing it in absolute methanol (100\%; Sigma-Aldrich) for $5 \mathrm{~d}$. Before using the MOF as an adsorbent, it was filtered, dried and heated in vacuum at $473 \mathrm{~K}$ overnight.

To synthesise UiO-66-30\%Al, $\mathrm{ZrCl}_{4}(1.5 \mathrm{~g})$ was mixed with terephthalic acid $(1.3 \mathrm{~g})$ in DMF $(60.2 \mathrm{~mL})$. After mixing for $15 \mathrm{~min}, \mathrm{Al}\left(\mathrm{NO}_{3}\right)_{3} .9 \mathrm{H}_{2} \mathrm{O}(0.45 \mathrm{~g})$ was added and then $5 \mathrm{~mL}$ of $\mathrm{H}_{2} \mathrm{O}$ was added to the mixture. The solution was mixed for approximately $30 \mathrm{~min}$. It was then moved to a $125-\mathrm{mL}$ Teflon-lined autoclave, which was tightly sealed and then placed in a preheated oven at $157^{\circ} \mathrm{C}$ for $1 \mathrm{~d}$. The white powder product of $\mathrm{UiO}-66-10 \% \mathrm{Al}$ was collected using a centrifuge machine and washed in DMF three times. The resultant product was dried in an oven and activated by immersing in absolute methanol (100\%; Sigma-Aldrich) for $5 \mathrm{~d}$. Before using the MOF as an adsorbent, it was filtered, dried and heated in a vacuum at $473 \mathrm{~K}$ overnight.

\subsection{Characterisation}

Thermogravimetric analysis (TGA) of the single-metal and bimetal Zr-MOFs was done using a TGA instrument (TGA/DSC1 STARe system; Mettler-Toledo). All MOF samples were placed in crucibles and transferred to the machine and heated at a rate of $5 \mathrm{~K} / \mathrm{min}$ until $1173 \mathrm{~K}$ when the air gas flow rate was maintained at $10 \mathrm{~mL} / \mathrm{min}$.

The stability of the functional groups on the organic linkers were assessed using Fourier transform infrared spectroscopy (FTIR; Spectrum 100 FT-IR spectrometer, PerkinElmer). A scanning process was undertaken by an attenuated total reflectance technique to obtain the FTIR 
spectra range 600 to $4000 \mathrm{~cm}^{-1}$ with a resolution of $4 \mathrm{~cm}^{-1}$.

To check the integrity of the MOF structure, X-ray powder diffraction patterns were obtained using an X-ray diffractometer (D8 Advance, Bruker AXS) with $\mathrm{Cu} \mathrm{Ka}$ radiation $(\lambda=1.5406 \AA)$, accelerating voltage $40 \mathrm{kV}$ and current $40 \mathrm{~mA}$.

$\mathrm{N}_{2}$ adsorption/desorption isotherms were performed using a Quantachrome instrument (Autosorb-1), and textural properties of the $\mathrm{Zr}$-MOFs were determined, such as pore size, pore volume and surface area. All MOFs were prepared by heat and vacuum for $1 \mathrm{~d}$ before loading to the machine to determine their adsorption properties.

\subsection{Adsorption Process}

An aqueous stock solution of $\mathrm{MO}(1000 \mathrm{ppm})$ was prepared by dissolving $\mathrm{MB}\left(\mathrm{C}_{16} \mathrm{H}_{18} \mathrm{ClN}_{3} \mathrm{~S}\right.$, molecular weight 319.85 g.mol ${ }^{-1}$; Sigma-Aldrich) in deionised water. Aqueous solutions with different concentrations of MB (5-100 ppm) were prepared by successive dilution of the stock solution with water, and $\mathrm{MB}$ concentrations were determined using absorbance at $668 \mathrm{~nm}$ wavelength of the solution after obtaining the UV spectra of the solution with a spectrophotometer (UV spectrophotometer). A calibration curve was obtained from spectra of the standard solutions ( 5 $-100 \mathrm{ppm})$. Prior to adsorption, the adsorbents were dried overnight in a vacuum at $373 \mathrm{~K}$. Several glass containers were cleaned, dried and filled to $20 \mathrm{~mL}$ with $\mathrm{MB}$ of different concentrations ranging from 5 to $50 \mathrm{ppm}$. Following this, an exact amount of an MOF adsorbent $(20 \mathrm{mg})$ was put in each glass container.

The dye solutions containing the adsorbents were mixed well by a magnetic stirrer and maintained for $5 \mathrm{~min}$ to $24 \mathrm{~h}$ at $298 \mathrm{~K}$. The samples for analysis were collected by syringe filter at different sampling intervals. A UV spectrometer was used to investigate the dye content in the supernatant.

\subsection{Adsorption Study}

The adsorption mechanism and rate of diffusion were estimated using three kinetic models: are pseudo secondorder [119], pseudo first-order [120] and intraparticle diffusion models [121]. Adsorption behaviours were simulated using the Langmuir [122] and Freundlich [123] adsorption isotherms.

\subsubsection{Kinetic Study}

Batch adsorption laboratory techniques were used to design the experiments. All practical kinetics experiments were conducted by preparing the specified initial concentrations $(5-50 \mathrm{mg} / \mathrm{L})$ and adding a predetermined dose of the adsorbent into a definite volume of $\mathrm{MB}$ solution at room temperature. Agitation was performed with a magnetic stirrer machine at $200 \mathrm{rpm}$ to optimise mass transfer and contact with the interfacial area for a predetermined time interval. MB concentration was measured using the supernatant at each predetermined time interval using a UV spectroscopy machine.

The amount of MB adsorbed onto UiO-66, UiO-66$10 \% \mathrm{Al}$ and $\mathrm{UiO}-66-33 \% \mathrm{Al}$ MOFs at any time was calculated using Equation 1 [124]. However, the percentage removal of $\mathrm{MB}$ was computed by Equation 2 [125].

$$
\begin{aligned}
q_{t} & =\left(C_{0}-C_{t}\right) \frac{V}{m} \\
R \% & =\frac{\left(C_{0}-C_{t}\right)}{C_{0}} X 100
\end{aligned}
$$

Where:

qt : the amount of MB adsorbed per unit weight of MOF at any time $\mathrm{t}(\mathrm{mg} / \mathrm{g})$

$\mathrm{C}_{0}$ : initial concentration of the $\mathrm{MB}$ solution at time zero $(\mathrm{mg} / \mathrm{L})$

$\mathrm{C}_{\mathrm{t}}$ : the concentration of $\mathrm{MB}$ solution at time $\mathrm{t}(\mathrm{mg} / \mathrm{L})$

$\mathrm{V}$ : volume of the $\mathrm{MB}$ solution in the batch adsorption process $(\mathrm{L})$

$\mathrm{R} \%$ : percentage removal of $\mathrm{MB}$

$\mathrm{m}$ : MOF mass used in the adsorption batch process $(\mathrm{g})$.

- Pseudo first-order model

The MOF removal of MB from simulated wastewater can be represented by a linear pseudo first-order model of adsorption $[120,126]$ expressed below:

$$
\ln \left(q_{e}-q_{t}\right)=\ln \left(q_{e}\right)-k_{1} t
$$

Where:

qe : the amount of $\mathrm{MB}$ adsorbed per unit weight of $\mathrm{MOF}$ at equilibrium $(\mathrm{mg} / \mathrm{g})$

qt : the amount of $\mathrm{MB}$ adsorbed per unit weight of $\mathrm{MOF}$ at any time $\mathrm{t}(\mathrm{mg} / \mathrm{g})$

$\mathrm{k} 1$ : pseudo first-order rate constant $\left(\mathrm{min}^{-1}\right)$

$\mathrm{t}$ : time ( $\mathrm{min})$.

The linear relationship between values of $\ln \left(q_{e}-q_{t}\right)$ and $t$ can be plotted as a straight line, from which $\mathrm{q}_{\mathrm{e}}$ and $\mathrm{k}_{1}$ can be found easily from the intercept and slope, respectively.

- Pseudo second-order model

The sorption kinetics of the MOF/MB system may also be described by a linearised form of the pseudo second-order model [119], based on adsorption equilibrium capacity expressed in the following form:

$$
\frac{t}{q_{t}}=\frac{1}{k_{2} \quad q_{e}^{2}}+\frac{1}{q_{e}} t
$$

Where:

qe : the amount of $\mathrm{MB}$ adsorbed per unit weight of $\mathrm{MOF}$ at equilibrium $(\mathrm{mg} / \mathrm{g})$

qt : the amount of MB adsorbed per unit weight of MOF at any time $\mathrm{t}(\mathrm{mg} / \mathrm{g})$

$\mathrm{t}$ : time (min)

$\mathrm{k} 2$ : pseudo second-order rate constant $(\mathrm{g} / \mathrm{mg} \mathrm{min})$.

The values of $\left(t / q_{t}\right)$ are linearly correlated with $t$, and the plot of $\left(t / q_{t}\right)$ against $t$ should be a straight line. The determination of $\mathrm{q}_{\mathrm{e}}$ and $\mathrm{k}_{2}$ can be done from the slope and intercept, respectively.

- Elovich kinetic model

The Elovich equation is generally used for chemisorption applications and can be written as follows: 


$$
\left(\frac{d q_{t}}{d t}\right)=\alpha \operatorname{Exp}\left(-\beta q_{t}\right)
$$

Where:

qt : the amount of MB adsorbed per unit weight of MOF at any time $\mathrm{t}(\mathrm{mg} / \mathrm{g})$

$\alpha \quad$ : a constant representing the initial rate of adsorption

$\beta$ : constant during any one experiment

$\mathrm{t}$ : time ( $\mathrm{min})$.

It appears that the initial adsorption rate at the beginning of contact time is not controlled by exponential law because when $\mathrm{q}_{\mathrm{t}}$ approaches zero, $\mathrm{dq}_{\mathrm{t}} / \mathrm{d}_{\mathrm{t}}$ equals $\alpha$ [127]. Integrating Equation 5 by assuming $q_{\mathrm{t}}=0$ at $t=0$, the result will be:

$$
q_{t}=\left(\frac{1}{\beta}\right) \ln (1+\alpha \cdot \beta t)
$$

If $\alpha \beta t>1$, the simple form of Equation 5.6 can be expressed as follows:

$$
q_{t}=\left(\frac{1}{\beta}\right) \ln (\alpha \cdot \beta)+\left(\frac{1}{\beta}\right) \ln (t)
$$

In a plot of the straight-line equation of $\mathrm{q}_{\mathrm{t}}$ as a function of $\ln$ $(t)$, the slope and intercept will be $(1 / \beta)$ and $(1 / \beta) \ln (\alpha \beta)$, respectively.

Equation 7 can facilitate the determination of the applicability of the Elovich kinetic equation on $\mathrm{MOF} / \mathrm{MB}$ systems [128].

\section{- Intraparticle diffusion model}

The intraparticle diffusion-based model is commonly used to test the mechanism of adsorption of pollutants onto a sorbent. This model is employed to identify the adsorption mechanism of MB onto MOF, and can be written as follows:

$$
q_{t}=k_{p} t^{1 / 2}+C
$$

Where:

$\mathrm{q}_{\mathrm{t}}$ : the amount of MB adsorbed per unit weight of MOF at any time $\mathrm{t}(\mathrm{mg} / \mathrm{g})$

$\mathrm{k}_{\mathrm{p}}$ : intraparticle diffusion rate constant $\left(\mathrm{mg} / \mathrm{g} \min ^{0.5}\right)$

$\mathrm{t} \quad$ : time $(\mathrm{min})$

C : intercept.

Based on this model, which is a linear relationship, the loading capacity is proportional to $\mathrm{t}^{1 / 2}$ as well as the intraparticle diffusion rate constant $\left(\mathrm{k}_{\mathrm{p}}\right) ; \mathrm{k}_{\mathrm{p}}$ and $\mathrm{C}$ can be determined from the slope and intercept of the intraparticle diffusion equation plot, respectively.

\subsubsection{Equilibrium Study}

Equilibrium studies were also performed in the same experiments carried out for kinetics studies. Agitation was done using a magnetic stirrer machine at $200 \mathrm{rpm}$ until the process reached equilibrium.

The amount of MB adsorbed onto UiO-66, UiO-66$10 \% \mathrm{Al}$ and $\mathrm{UiO}-66-30 \% \mathrm{Al} \mathrm{MOF}$ at equilibrium can be expressed by Equation (2) [129]:

$$
q_{e}=\left(C_{0}-C_{e}\right) \frac{V}{m}
$$

Where:

$\mathrm{q}_{\mathrm{e}}$ : the amount of MB adsorbed per unit weight of MOF at equilibrium $(\mathrm{mg} / \mathrm{g})$

$\mathrm{C}_{0}$ : initial concentration of $\mathrm{MB}$ solution at time zero (mg/L)

$\mathrm{C}_{\mathrm{e}}$ : concentration of $\mathrm{MB}$ solution at equilibrium $(\mathrm{mg} / \mathrm{L})$

$\mathrm{V}$ : volume of $\mathrm{MB}$ solution in batch adsorption process (L)

$\mathrm{m}$ : MOF mass used in the adsorption batch process $(\mathrm{g})$.

- Isotherm models

Identifying an adsorption isotherm is essential for describing the interaction of the pollutant $(\mathrm{MB})$ with the adsorbent (MOF), so that the adsorbent can be optimised [130]. The two common isotherms are the Langmuir [131] and the Freundlich [123] isotherms.

- The Langmuir models

A nonlinear form of the Langmuir isotherm model can be expressed as:

$$
q_{e}=\frac{q_{m} k_{L} C_{e}}{\left(1+k_{L} C_{e}\right)}
$$

It is possible to linearise the Langmuir isotherm equation to give the following:

$$
\frac{C_{e}}{q_{e}}=\frac{1}{q_{m}} C_{e}+\frac{1}{k_{L} q_{m}}
$$

Where:

$\mathrm{q}_{\mathrm{m}}$ : Langmuir maximum loading capacity $(\mathrm{mg} / \mathrm{g})$

$\mathrm{K}_{\mathrm{L}}$ : Langmuir constant related to the energy of adsorption and affinity of binding sites $(\mathrm{L} / \mathrm{mg})$

$\mathrm{C}_{e}$ : the equilibrium concentration of adsorbate $(\mathrm{mg} / \mathrm{L})$

$\mathrm{q}_{\mathrm{e}}$ : adsorption capacity at equilibrium $(\mathrm{mg} / \mathrm{g})$.

A plot of $C_{e} / q_{e}$ versus Ce should obtain a linear relationship. Therefore, $\mathrm{q}_{\mathrm{m}}$ and $\mathrm{K}_{\mathrm{L}}$ can be determined from the slope and intercept of the plot.

The dimensionless constant separation factor $R_{\mathrm{L}}$ is an important characteristic of the Langmuir isotherm that can be represented by the following equation [96, 132-134]:

$$
R_{L}=\frac{1}{\left(1+k_{L} C_{0}\right)}
$$

Where:

$\mathrm{C}_{0}$ : initial concentration of $\mathrm{MB}(\mathrm{mg} / \mathrm{L})$

$\mathrm{K}_{\mathrm{L}}$ : Langmuir constant $(\mathrm{L} / \mathrm{mg})$.

The value of $R_{L}$ plays a very important role in the shape of the isotherm because it indicates the adsorption process is: unfavourable $(\mathrm{RL}>1)$, linear $(\mathrm{RL}=1)$, favourable $(0<\mathrm{RL}<1)$, irreversible $(\mathrm{RL}=0)$.

- The Freundlich models

The nonlinear model of the Freundlich isotherm [123] can be expressed as:

$$
q_{e}=k_{F} C_{e}^{1 / n}
$$

The linear equation of the Freundlich isotherm can be expressed as $[15,135]$ : 


$$
\ln \left(q_{e}\right)=\ln \left(k_{F}\right)+\frac{1}{n} \ln \left(C_{e}\right)
$$

Where:

$\mathrm{K}_{\mathrm{F}}$ : the calculated Freundlich equilibrium constant $\left([\mathrm{mg} / \mathrm{g}][\mathrm{L} / \mathrm{mg}]^{1 / \mathrm{n}}\right)$ as an indicator of adsorption capacity

$\mathrm{n}$ : a measure of the deviation from linearity of adsorp tion $(\mathrm{g} / \mathrm{L})$.

A plot of $\ln \left(\mathrm{q}_{\mathrm{e}}\right)$ versus $\ln (\mathrm{Ce})$ should obtain a linear relationship; therefore, $n$ and $\mathrm{K}_{\mathrm{F}}$ can be determined from the slope and intercept of the plot.

If the value of $\mathrm{n}>1$, it is good indication that the adsorption process is favourable.

\section{RESULTS AND DISCUSSION}

\subsection{Characterisation}

As shown in Figure 1(a), the XRD pattern for the modified bimetal Zr-MOF (UiO-66-10\%Al and UiO-66$30 \% \mathrm{Al}$ ), in contrast to the parent single-metal $\mathrm{Zr}-\mathrm{MOF}$ (UiO-66) before and after use, verify the phase purity and structural integrity of the MOF samples. Therefore, they are good signs of successful synthesis and activation of MOFs with pores free of oxide contaminants. Furthermore, Figure 1(a) show also the XRD patterns of the same abovementioned MOFs after use in adsorption process.

Figure 1(b) illustrates FTIR spectra of parent (UiO66) and modified bimetal $\mathrm{Zr-MOF}$ (UiO-66-10\%Al and UiO-66-30\%Al) before and after use. According to FTIR spectra of the three Zr-MOFs (single-metal and bimetal samples) shown in Figure 1(b), the application of the same vibration bands resulted in a slight deviation in the position of some peaks for the bimetal samples, with broader peaks verifying a difference in the dipole between ground state and excited state of bimetal $\mathrm{Zr}$ - MOFs due to incorporation of the second metal centre $[136,137]$. The extension of the vibration bands of bimetal MOFs was 1590 to $1525 \mathrm{~cm}^{-1}$; it was originally in the range 1615 to $1580 \mathrm{~cm}^{-1}$ because of $\mathrm{C}=\mathrm{C}-\mathrm{C}$ stretching in the aromatic ring of terephthalate salts [138]. In addition, the FTIR spectrum shows the stretching vibration of symmetric $\mathrm{COO}^{-}$and asymmetric $\mathrm{COO}^{-}$in organic linkers at bands 1500 and $1390 \mathrm{~cm}^{-1}$. However, bands at 881,812 and $785 \mathrm{~cm}^{-1}$ were assigned to $\mathrm{Zr}-\mathrm{O}$ stretching. In addition, stretching vibration of C-H at 730 $\mathrm{cm}^{-1}$ was attributed to the out-of-plane bending of aromatic ring of UiO-66, in comparison with that at $744 \mathrm{~cm}^{-1}$ attributed to the spectrum of bimetal $\mathrm{Zr}$-MOF $[137,139]$ and the stretching vibration of $\mathrm{C}-\mathrm{H}$ at $1017 \mathrm{~cm}^{-1}$ to $\mathrm{Zr}$ MOF.

Thermal stability of $\mathrm{UiO}-66, \mathrm{UiO} 66-10 \% \mathrm{Al}$ and UiO66-30\%Al was investigated using a TGA machine (TGA/DSC1 STARe system; Mettler-Toledo). The results of thermogravimetric analysis of all $\mathrm{Zr}$-MOFs (single-metal and bimetal) are shown in Figure 1(c). They validate the thermal stability and structural robustness up to $725 \mathrm{~K}$ with a continuous mass loss of $15 \%$ and $25 \%$ for bimetal and single-metal MOFs, respectively. However, the variation in the weight loss of the samples is due to pre-treatment (dehydrated and hydrated) and solvent molecules in the pore interior of the material [140].

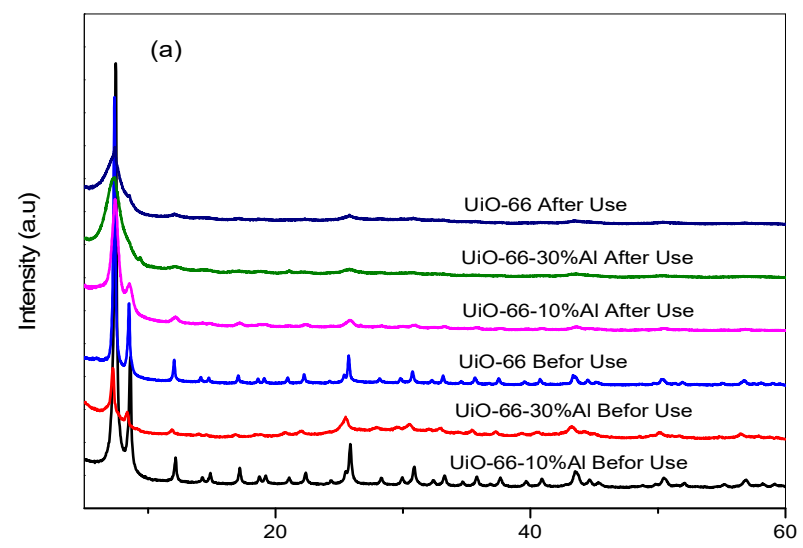

$(2 \theta)^{\circ}$
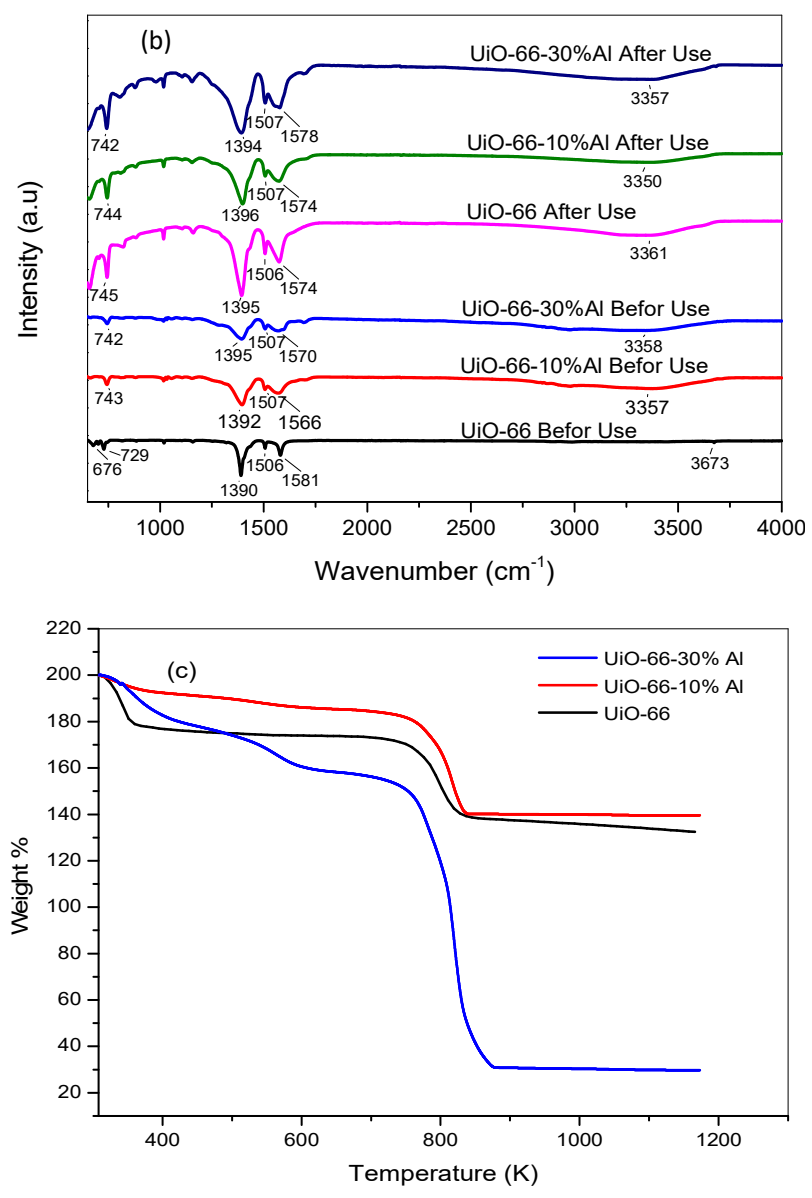

Fig. 1. Characterisation of metal organic framework samples: (a) PXRD patterns, (b) FTIR spectra and (c) TGA profiles of pristine and modified $\mathrm{UiO}-66$ samples.

Measurements of $\mathrm{N}_{2}$ adsorption/desorption isotherms, pore size and surface area of $\mathrm{Zr}$-MOFs (single-metal and bimetal) were obtained (Autosorb-1, Quantachrome Instruments). The isotherms of UiO-66-Al and UiO-66 are illustrated in Figure 2(a) and (b). According to Figure 2(a), the parent UiO-66 MOF exhibits the analogous of type IV adsorption-desorption isotherm, which is proof of a typical mesoporous network. Moreover, hysteresis from 0.1-1.0 relative pressure indicates a homogeneous pore size distribution [2].

On the other hand, Figure 2(b) shows hysteresis in the desorption isotherm of $\mathrm{UiO}-66-10 \% \mathrm{Al}$ and rapid increase in 
Table 1 Textural properties of adsorbents based on $\mathrm{N}_{2}$ adsorption/isotherms.

\begin{tabular}{cccc}
\hline Adsorbents & $\begin{array}{c}\text { Specific surface area } \\
\left(\mathrm{S}_{\mathrm{BET}}\right)\left(\mathrm{m}^{2} \mathrm{~g}^{-1}\right)\end{array}$ & $\begin{array}{c}\text { Pore volume } \\
\left(\mathrm{cc} \mathrm{g}^{-1}\right)\end{array}$ & $\begin{array}{c}\text { Pore diameter } \\
(\mathrm{nm})\end{array}$ \\
\hline UiO-66 & 1585.5 & 0.82 & 1.04 \\
$\mathrm{UiO}-66-10 \% \mathrm{Al}$ & 1145.953 & 1.34 & 2.33 \\
$\mathrm{UiO}-66-30 \% \mathrm{Al}$ & 769.011 & 0.39 & 1.01 \\
\hline
\end{tabular}
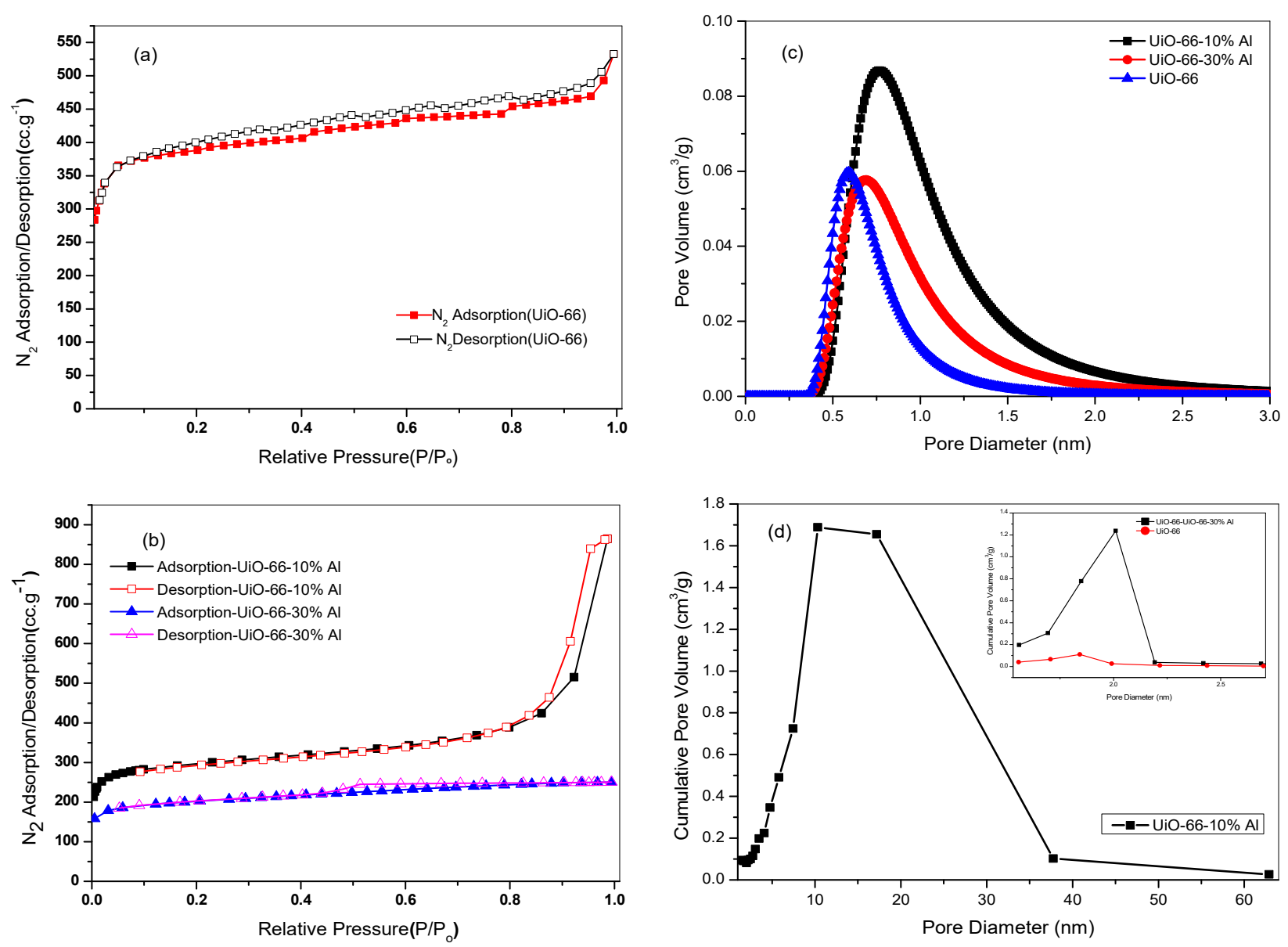

Fig. 2. $\mathrm{N}_{2}$ adsorption/desorption isotherm of UiO-66 (a), $\mathrm{N}_{2}$ adsorption/desorption isotherms of UiO-66-Al samples (b), micropore distribution (c)and mesopore distribution (d) of. UiO-66, UiO-66-10\% $\mathrm{Al}$ and UiO-66-30\% $\mathrm{Al}$.

adsorption at approximate relative pressure equal to 0.999, indicating improving mesopore and macropore size. Based on the $\mathrm{N}_{2}$ adsorption-desorption isotherms, the values for the surface area, pore volume and pore size (textural properties) of Zr-MOF were calculated and listed in Table 1. These values indicate decreases in the specific surface area $\left(S_{\mathrm{BET}}\right)$ with increases in the percentage of the second metal. That is, the $S_{\mathrm{BET}}$ gradually decreased from $1585.5 \mathrm{~m}^{2} \mathrm{~g}^{-1}$ in UiO-66 to become $1145.953 \mathrm{~m}^{2} \mathrm{~g}^{-1}$ in UiO-66-10\%Al, and reached $769.011 \mathrm{~m}^{2} \mathrm{~g}^{-1}$ in $\mathrm{UiO}-66-30 \% \mathrm{Al}$.

In contrast, the pore volume and diameter were enlarged in $\mathrm{UiO}-66-10 \% \mathrm{Al}$, at $1.34 \mathrm{cc} \mathrm{g}^{-1}$ and $2.33 \mathrm{~nm}$, respectively. The reason for such augmentation is attributable to the replacement of methanol molecules by the second metal in the first activation process involving solvent exchange and discarding it in the second activation process by heating and vacuum.

\subsection{Kinetic Studies}

Studies of kinetics are an essential part of a sorption process to enable the researchers to determine the rate and mechanism of adsorption [141]. To investigate the adsorption mechanism, including the mass transfer and chemical reaction [2], experimental data were examined using pseudo first-order, pseudo second-order and Elovich models. All the information and parameters relating to mechanism of adsorption can be obtained via adsorption kinetics, which are vital in treatment of aqueous effluent [142].

The adsorption process of the three solid /liquid (MOF/MB) systems were examined using pseudo first-order, pseudo second order [143-145] and Elovich models $[128,141,146]$. The key feature of these equations is the ease with which adsorption properties (e.g., adsorption capacity, rate constant) can be assigned, and the initial 
adsorption rate can be easily found from the linear equations of these models without previous knowledge of any parameter.

As adsorption processes involve chemisorption, they can be described by pseudo second-order rate expression [143-145] and Elovich model [128, 141, 146]. Moreover, the pseudo second-order model showed the highest linear correlation coefficient $\left(\mathrm{R}^{2}\right)$ and therefore, the highest agreement with the kinetics experimental data than did the Elovich model, for all MB/Zr-MOF systems.

The pseudo first-order equation did not fit well for the entire range of reactions in all $\mathrm{MOF} / \mathrm{MB}$ systems. In general, the equation was only applicable to the first 20 or $30 \mathrm{~min}$ of the adsorption interaction process this is consistent with the reported literature [147-160]. Consequently, the MOF/MB systems did not fit the pseudo first-order equation for the whole range of contact time.

Kinetics adsorption studies are crucial indicators of a criteria of adsorbent efficiency (i.e., the rate of adsorption) and provide a clear picture of the mechanism of adsorption.

Figure 3 below explains the variation in the amount of adsorbate on adsorbent $\left(q_{t}\right)$ as a function of contact time. The rate of $\mathrm{MB}$ adsorption was high at the beginning of the sorption process before slowing as the reaction progressed until reaching an equilibrium saturation. That the rate of adsorption was faster at the start may be due to the accessibility of adsorptive sites of the MOFs [161, 162]. The adsorption of $\mathrm{MB}$ by $\mathrm{UiO}-66-10 \% \mathrm{Al}$ took less time than by the other two MOFs, which indicate that the rate of dye sorption by $\mathrm{UiO}-66-10 \% \mathrm{Al}$ was the quickest among the three MOFs examined.

Figure 3 also illustrates the dependency of MB uptake on contact time given different initial concentrations of $\mathrm{MB}$. It confirms that higher initial concentrations of $\mathrm{MB}$ lead to increases in adsorption capacity for MB dye. Consequently, MB uptake per unit mass of MOF, or adsorption density, also increases. Specifically, higher initial concentrations of MB may reduce accessibility of adsorption sites, which can increase the amount of adsorbate on adsorbent [163]. The increase in adsorption density or capacity with higher initial concentrations of $\mathrm{MB}$ is generally due to the availability of unsaturated adsorption sites on the surface of MOFs during the sorption batch process $[164,165]$.

To analyse the adsorption kinetics of the dye/MOF system, pseudo first-order [120], pseudo second-order [166] and Elovich equations [127] were examined. Tables 2 and 3 present the resultant values of the parameters fitted to the pseudo second order and Elovich models, respectively.

There pseudo first-order equation was not a good fit for the entire range of reactions in all $\mathrm{MOF} / \mathrm{MB}$ systems; however, it can be generally applied to the first 20 or $30 \mathrm{~min}$ of the adsorption interaction process. This is consistent with the reported literature [147]. Consequently, the MOF/MB systems did not obey the equation during the whole of the contact time through the equation was mostly valid for the initial stage of the sorption process. In addition, the experimental $\mathrm{q}_{\mathrm{e}}$ values, which can be obtained from the intercept of the linear relationship between $\ln \left(q_{e}-q_{t}\right)$ and time, did not agree with the computed values. These results are proof that the adsorption of $\mathrm{MB}$ onto $\mathrm{Zr}$-MOFs (single-metal and bimetal) is not based on first-order kinetics [94].

The obtained experimental data were further fitted to the pseudo second-order equation. The values for $\mathrm{q}_{\mathrm{e}}$ and $\mathrm{k}_{2}$ were obtained from the slope and intercept of the linear plots of $\left(t / q_{t}\right)$ versus $t$, respectively, and listed in Table 2 . Figure 3(b), (d) and (f) show that MB uptake by Zr-MOF increased with increases in contact time for each of the different initial MB concentrations, as well as at higher initial MB concentrations. The correlation coefficients of the plots showed that the pseudo second-order equation had the best fit with the experimental data, with the range of $\mathrm{R}^{2}$ values (0.9953-0.9999) listed in Table 2 . These results verify the agreement of this kinetic model and the second-order behaviour of the adsorption process of MB by Zr-MOFs. Based on the linear regression correlation coefficient values $\left(\mathrm{R}^{2}\right)$, the nature of the sorption process over the whole range of contact time for all solid/liquid systems in this study can be considered a chemisorption mechanism, as the ratecontrolling step related to valence forces of sharing or exchanging electrons between $\mathrm{Zr}-\mathrm{MOF}$ and MB.

The results of the correlational analysis of the amount of dye adsorbed $(\mathrm{mg} / \mathrm{g})$ against contact time for four initial $\mathrm{MB}$ concentrations $(5,15,30$ and $50 \mathrm{ppm})$ are shown in Figure 3. The results indicate that the amount of dye loading, $\mathrm{q}_{\mathrm{t}}(\mathrm{mg} / \mathrm{g})$, increased with contact time for each concentration separately.

The Elovich model can be applied to the chemisorption reaction; it is a model reasonably employed in chemisorption processes and to a wide range of slow adsorption processes. Specifically, this model may facilitate those systems for which the adsorption surface is heterogeneous.

Experimental data of $\mathrm{MOF} / \mathrm{MB}$ batch adsorption systems were incorrectly described using the pseudo firstorder model. Further, these systems can be represented by a combination of two or three sequential and instantaneous pseudo first-order reactions. The basic form of the Elovich equation described the experimental data well; however, the Elovich equation can be easily fitted to the experimental data using one straight line to describe the whole progress of contact time [128].

The experimental data were also examined with respect to the Elovich model, with the values of all parameters derived and the slope and intercept of the linear relationship indicating the constants $\alpha$ and $\beta$, respectively. In addition, these constants can be comparison parameters of reaction rates of $\mathrm{MB}$ adsorption in the various kinds of $\mathrm{Zr}-\mathrm{MOF}$; the values of $\alpha$ and $\beta$, derived from the linear plots of $q_{t}$ versus $\ln$ $(\mathrm{t})$, are listed in Table 3. According to the Elovich model, the increase in $\alpha$ and/or the decrease in $\beta$ should increase the adsorption rate, which in turn increases $\mathrm{MB}$ uptake. Therefore, the relative loading of the three $\mathrm{Zr}$-MOFs are $\mathrm{UiO}-66-10 \% \mathrm{Al}>\mathrm{UiO}-66-30 \% \mathrm{Al}>\mathrm{UiO}-66$ [128].

Figure 3(a), (c) and (e) illustrate the changes in Zr-MOFs capacities at different initial MB concentrations with time. Loading capacities are increased with increasing contact time at each initial concentration, and with higher initial $\mathrm{MB}$ concentrations. Based on the values of the correlation coefficient $\left(\mathrm{R}^{2}\right)$ and the fact that higher $\mathrm{R}^{2}$ values reflect better bit with the adsorption kinetics model, the best 
fit for the experimental data was exhibited by the Elovich equation model for all $\mathrm{MB} / \mathrm{MOF}$ systems (single-metal and bimetal). The range of $\mathrm{R}^{2}$ values $(0.9242-0.9986)$ is listed in
Table 3. These results indicate and emphasise that all the investigated sorption systems obey chemisorption kinetics.

Table 2 Calculated kinetics constant $\left(\mathrm{k}_{2}\right)$ and correlation coefficient $\left(\mathrm{R}^{2}\right)$ of the pseudo second-order model for $\mathrm{C}_{\mathrm{i}}=5$, 15,30 and $50 \mathrm{mg} / \mathrm{L}$.

Pseudo second-order kinetics constant $\mathrm{k}_{2}$ (g/[mg.min])

\begin{tabular}{lccccccccc}
\cline { 3 - 9 } \multicolumn{1}{c}{ Adsorbent } & Adsorbate & \multicolumn{2}{c}{$5 \mathrm{ppm}$} & \multicolumn{2}{c}{$15 \mathrm{ppm}$} & \multicolumn{2}{c}{$30 \mathrm{ppm}$} & \multicolumn{2}{c}{$50 \mathrm{ppm}$} \\
\cline { 3 - 10 } & & $\mathrm{k}_{2}$ & $\mathrm{R}^{2}$ & $\mathrm{k}_{2}$ & $\mathrm{R}^{2}$ & $\mathrm{k}_{2}$ & $\mathrm{R}^{2}$ & $\mathrm{k}_{2}$ & $\mathrm{R}^{2}$ \\
\hline UiO-66 & $\mathrm{MB}$ & 0.01050 & 0.9989 & 0.00546 & 0.9992 & 0.00273 & 0.9992 & 0.00147 & 0.9990 \\
UiO-66-10\% Al & $\mathrm{MB}$ & 1.34913 & 0.9999 & 0.01560 & 0.9997 & 0.00653 & 0.9995 & 0.00158 & 0.9953 \\
UiO-66-30\% Al & MB & 0.00520 & 0.9977 & 0.00212 & 0.9984 & 0.00060 & 0.9975 & 0.00074 & 0.9990
\end{tabular}
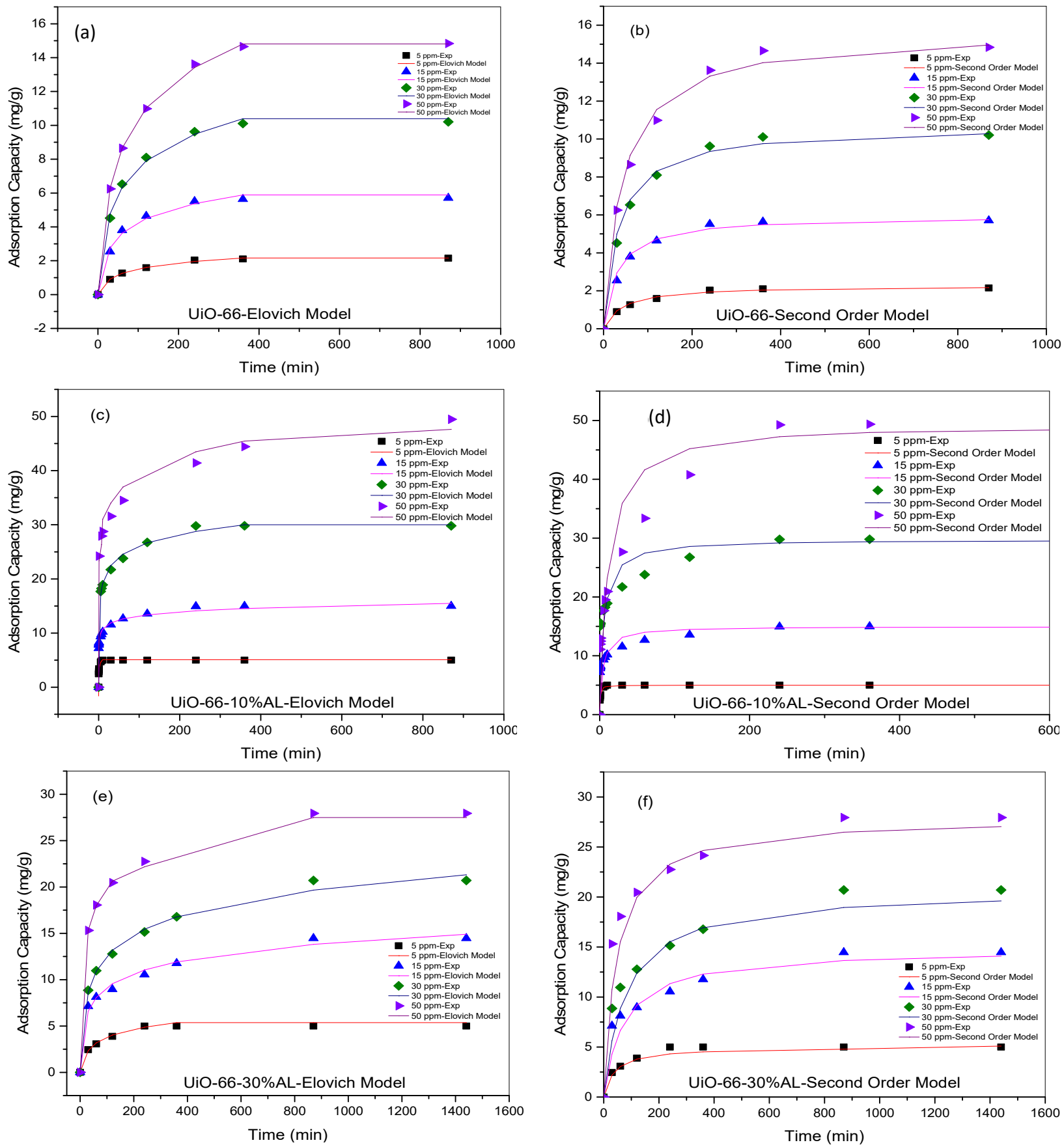

Fig. 3. Fitting of experimental data using Elovich and second-order kinetics models of $\mathrm{MB}$ adsorption $\mathrm{MB}$ onto UiO-66 (a, b), $\mathrm{UiO}-66-10 \% \mathrm{Al}$ (c, d) and $\mathrm{UiO}-66-30 \% \mathrm{Al}(\mathrm{e}, \mathrm{f})$. 


\subsection{Intraparticle diffusion studies}

In addition, the intraparticle diffusion model

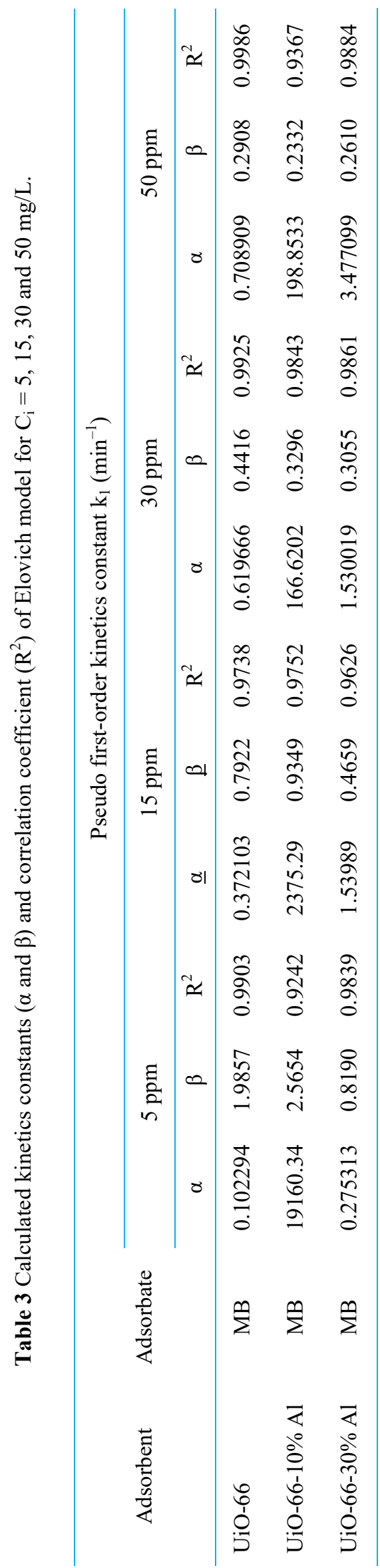
suggested by Weber and Morris [121] was utilise to recognise the diffusion mechanism. Based on this model, the loading $\mathrm{q}_{\mathrm{t}}$ against the square root of the contact time varies almost proportionally. Further, intraparticle diffusion models are vital to identifying the steps involved in the adsorption process to facilitate understanding of the adsorption mechanism [167].
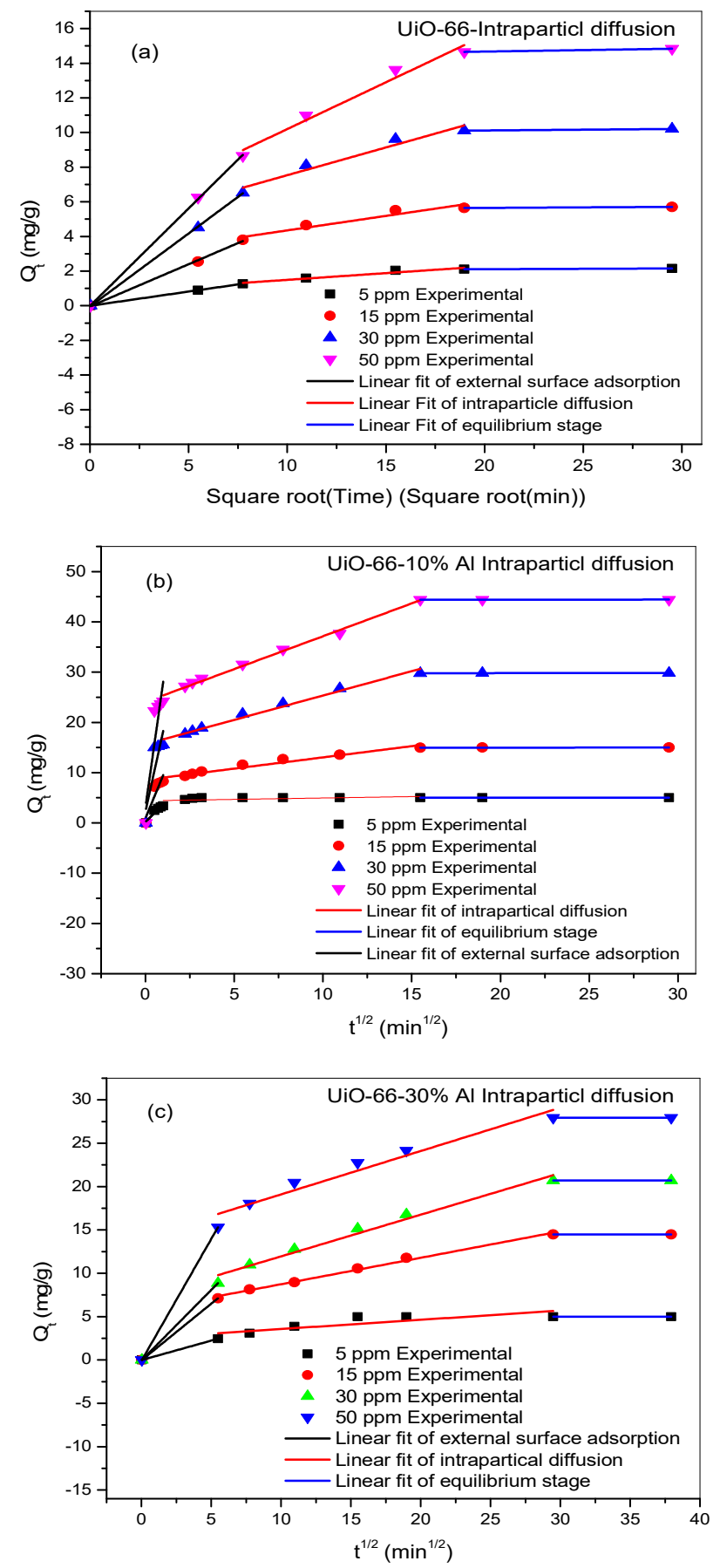

Fig. 4. Fitting of experimental data using intraparticle diffusion models of $\mathrm{MB}$ adsorption onto UiO-66 (a), UiO66-10\%Al (b) and UiO-66-30\%Al (c). 
Table 4 Calculated kinetics constant $\left(\mathrm{k}_{\mathrm{p}}\right), \mathrm{C}$ and correlation coefficient $\left(\mathrm{R}^{2}\right)$ for $\mathrm{C}_{\mathrm{i}}=5,15,30$ and $50 \mathrm{ppm}$.

\begin{tabular}{ccccc}
\hline & \multicolumn{4}{c}{ Adsorption mechanism } \\
\cline { 2 - 5 } Adsorbent & \multicolumn{4}{c}{ Intraparticle diffusion model } \\
\cline { 2 - 5 } & $\begin{array}{c}\text { Initial concentration of } \\
\text { MB solution }\left(\mathrm{mg} \mathrm{L}^{-1}\right)\end{array}$ & $\begin{array}{c}\mathrm{k}_{\mathrm{p}} \\
\left(\mathrm{mg} \mathrm{g}^{-1} \mathrm{~min}^{-(1 / 2)}\right)\end{array}$ & $\begin{array}{c}\mathrm{C} \\
\left(\mathrm{mg} \mathrm{g}^{-1}\right)\end{array}$ & $\mathrm{R}^{2}$ \\
\hline UiO-66 & 5 & 0.0991 & 0.5017 & 0.9999 \\
UiO-66-10\%Al & 15 & 0.22 & 2.1455 & 0.9918 \\
& 30 & 0.3955 & 3.5763 & 0.9884 \\
& 50 & 0.638 & 3.8144 & 0.9959 \\
UiO-66-30\%Al & 5 & 0.4314 & 3.8489 & 0.9850 \\
& 15 & 0.5717 & 7.9333 & 0.9552 \\
& 30 & 1.011 & 15.226 & 0.9797 \\
& 50 & 1.1428 & 24.123 & 0.9720 \\
& 5 & 0.2536 & 1.0889 & 0.9994 \\
& 15 & 0.2958 & 5.8863 & 0.9947 \\
& 30 & 0.4446 & 7.9245 & 0.9901 \\
& 50 & 0.4402 & 15.395 & 0.9775
\end{tabular}

The lack of descriptions of the adsorption mechanism and rate-controlling step of the adsorption process are some of the limitations of the pseudo first-order, pseudo second order and Elovich kinetic models. In response to these limitations, Weber and Morris created the intraparticle diffusion model [168]. The migration of the pollutant (MB) from bulk phase to the surface of the sorbent (Zr-MOFs) can be either by film or external diffusion, pore diffusion, surface diffusion and adsorption on the pore surface, or a combination of more than one of these steps [169].

Figure 4 plots the $q_{t}$ against $t^{1 / 2}$ rather than $t$, for the various initial $\mathrm{MB}$ concentrations. Linear variations in uptake with $t^{1 / 2}$ is gained for a certain initial fraction of the reaction. The straight-line plot of qt versus $\mathrm{t}^{1 / 2}$ may provide the values of the intraparticle diffusion rate constant $\mathrm{k}_{\mathrm{p}} ; \mathrm{k}_{\mathrm{p}}$ and $\mathrm{C}$ can be found from the slope and intercept of the model, respectively. Table 4 lists these values as well as the correlation coefficients $\left(\mathrm{R}^{2}\right)$ for the initial $\mathrm{MB}$ concentrations $5,15,30$ and $50 \mathrm{mg} / \mathrm{L}$. The focus of the intraparticle diffusion model is on the second linear portion of the plot, in which the slope characterises the rate constant $\left(\mathrm{k}_{\mathrm{p}}\right)$ while the intercept $(\mathrm{C})$ is related to the thickness of the boundary layer [15].

Figure 4 illustrates the three stages of the adsorption mechanism, which are represented by the three linear relationships. The first part of the plot is inclined sharply, indicating rapid sorption or external surface adsorption. The second part represents the rate-controlling step which is intraparticle diffusion, the slowest stage of adsorption [170]. The last part is the equilibrium where the processes of adsorption of $\mathrm{MB}$ onto $\mathrm{Zr}$-MOFs reach a plateau because either the active adsorptive sites on MOFs have been occupied or the concentration of $\mathrm{MB}$ in the solution is extremely low [95]. Specifically, Figure 4 shows that the second straight line does not pass through the origin or initial point of adsorption because of variations in mass-transfer rate between the saturation and equilibrium steps of sorption [171-174]. In addition, this kind of deviation from the origin is proof that pore diffusion is not the only rate-limiting factor [175].

\subsection{Equilibrium studies}

A set of batch experiments was conducted with various initial MB concentrations: 5, 15, 30 and $50 \mathrm{mg} / \mathrm{L}$. The one factor allowed us to vary concentrations of $\mathrm{MB}$ while maintaining other process factors like MOF dose, stirrer speed, volume of the solution and temperature unchanged. Data from the equilibrium experiments were investigated using Langmuir [131] and Freundlich [123] isotherms.

The assumption of the Langmuir isotherm theory is described as monolayer coverage of adsorbate (MB) onto a homogenous adsorbent (Zr-MOFs) surface [131]. Hence, its basic assumption is that sorption takes place at specific homogeneous sites on the adsorbent. As soon as an adsorbent site is occupied by an MB molecule, no additional adsorption can occur at that site again.

The equilibrium data were examined using a Langmuir model. The values of the parameters and constants, together with the $\mathrm{R}^{2}$ values, were obtained from the slope and intercept of the linear plot and listed in Table 5. Figure 5(a), (b) and (c) illustrate the experimental equilibrium data and the predicted theoretical Langmuir isotherm for the adsorption process of $\mathrm{MB}$ onto $\mathrm{Zr}-\mathrm{MOF}$ (single-metal and bimetal).

The fundamental characteristics of the Langmuir model can be expressed in terms of a dimensionless constant 
separation factor, $\mathrm{R}_{\mathrm{L}}$, or Equation 12 [133]. The value of $\mathrm{R}_{\mathrm{L}}$ is an indication of the shape of the isotherm. Basically, the $R_{L}$ value determines the favourability of the adsorption process, which can be either unfavourable $(R L>1)$, linear $(R L=1)$, favourable $(0<R L<1)$ or irreversible $(R L=0)$. The equilibrium analysis revealed that the $\mathrm{R}_{\mathrm{L}}$ values were between 0 and 1, indicating a favourable adsorption process for all $\mathrm{MB}$ / Zr-MOF (single-metal and bimetal) systems.

The Freundlich model [123] is an empirical equation that assumes the adsorption process can occur on heterogeneous surfaces and that the adsorption capacity depends on the concentration of MB. According to Equation 13, equilibrium adsorption properties such as $\mathrm{k}_{\mathrm{F}}$ and $(1 / \mathrm{n})$ are rough indicators of the adsorption capacity and the adsorption intensity, respectively. The favourability of the adsorption process can be determined from the magnitude of the exponent $(1 / n)$; the criterion for a favourable adsorption is that the values of $\mathrm{n}$ must be greater than one [176].
The equilibrium data were further tested by the Freundlich isotherm model. Freundlich isotherm constants and correlation coefficient $\left(\mathrm{R}^{2}\right)$ values are tabulated in Table 5. As shown in Table 5, the correlation coefficient of the Freundlich isotherm for all $\mathrm{MB} / \mathrm{MOF}$ systems were higher than those based on the Langmuir model, proving strong linearity. The analysis verified that the values of $\mathrm{n}$ for all systems were greater than one, as tabulated in Table 5. Such a result is solid confirmation of favourable adsorption and easy loading of MB onto Zr-MOFs from aqueous solutions [177].

The maximum Langmuir adsorption capacity was exhibited by UiO-66-10\%Al, with $\mathrm{q}_{\mathrm{m}}$ of $49.26 \mathrm{mg} / \mathrm{g}$. Furthermore, the comparative adsorption capacity of $\mathrm{Zr}-\mathrm{MOF}$ for $\mathrm{MB}$ in this study, relative to that of other adsorbents reported in the literature, is provided in Table 6.

Table 5 Calculated equilibrium constants $\left(\mathrm{k}_{\mathrm{L}}, \mathrm{k}_{\mathrm{F}}, \mathrm{q}_{\mathrm{m}}, \mathrm{n}\right.$ and correlation coefficient $\left.\left(\mathrm{R}^{2}\right)\right)$ of $\mathrm{MB}$ adsorption onto UiO-66, UiO66-10\% Al and $\mathrm{UiO}-66-30 \% \mathrm{Al}$ for $\mathrm{C}_{\mathrm{i}}=5,15,30$ and $50 \mathrm{mg} / \mathrm{L}$.

\begin{tabular}{|c|c|c|c|c|}
\hline Adsorbent & $\begin{array}{l}\text { Adsorption isotherm } \\
\text { model }\end{array}$ & Parameter & Value & $\mathrm{R}^{2}$ \\
\hline \multirow{4}{*}{ UiO-66 } & \multirow{2}{*}{ Langmuir } & $\mathrm{q}_{\mathrm{m}}(\mathrm{mg} / \mathrm{g})$ & 14.52 & \multirow{2}{*}{0.9889} \\
\hline & & $\mathrm{K}_{\mathrm{L}}(\mathrm{L} / \mathrm{mg})$ & 0.02447 & \\
\hline & \multirow{2}{*}{ Freundlich } & $\mathrm{K}_{\mathrm{F}}\left([\mathrm{mg} / \mathrm{g}][\mathrm{L} / \mathrm{mg}]^{1 / \mathrm{n}}\right)$ & 0.98157 & \multirow{2}{*}{0.9979} \\
\hline & & $\mathrm{n}(\mathrm{g} / \mathrm{L})$ & 1.2918 & \\
\hline \multirow{4}{*}{ UiO-66-10\%Al } & \multirow{2}{*}{ Langmuir } & $\mathrm{q}_{\mathrm{m}}(\mathrm{mg} / \mathrm{g})$ & 49.26 & \multirow{2}{*}{0.9396} \\
\hline & & $\mathrm{K}_{\mathrm{L}}(\mathrm{L} / \mathrm{mg})$ & 29 & \\
\hline & \multirow{2}{*}{ Freundlich } & $\mathrm{K}_{\mathrm{F}}\left([\mathrm{mg} / \mathrm{g}][\mathrm{L} / \mathrm{mg}]^{1 / \mathrm{n}}\right)$ & 53.53 & \multirow{2}{*}{0.9711} \\
\hline & & $n(g / L)$ & 4.05 & \\
\hline \multirow{4}{*}{$\mathrm{UiO}-66-30 \% \mathrm{Al}$} & \multirow{2}{*}{ Langmuir } & $\mathrm{q}_{\mathrm{m}}(\mathrm{mg} / \mathrm{g})$ & 27.85 & \multirow{2}{*}{0.9777} \\
\hline & & $\mathrm{K}_{\mathrm{L}}(\mathrm{L} / \mathrm{mg})$ & 1.10 & \\
\hline & \multirow{2}{*}{ Freundlich } & $\mathrm{K}_{\mathrm{F}}\left([\mathrm{mg} / \mathrm{g}][\mathrm{L} / \mathrm{mg}]^{1 / \mathrm{n}}\right)$ & 16.71 & \multirow{2}{*}{0.9888} \\
\hline & & $\mathrm{n}(\mathrm{g} / \mathrm{L})$ & 7.52 & \\
\hline
\end{tabular}

Table 6 Comparison of monolayer equilibrium capacity for methylene blue onto different sorbents.

\begin{tabular}{lccc}
\hline \multicolumn{1}{c}{ Adsorbent } & Condition & $\begin{array}{c}\mathrm{q}_{\mathrm{m}} \\
(\mathrm{mg} / \mathrm{g})\end{array}$ & $\begin{array}{c}\text { Reference } \\
\text { UiO-66-10\%Al }\end{array}$ \\
UiO-66-30\%Al & Normal & 49.26 & $\begin{array}{c}\text { This study } \\
\text { UiO-66 }\end{array}$ \\
Tobacco stem ash & Normal & 35.85 & $\begin{array}{c}\text { This study } \\
\text { This study }\end{array}$ \\
Oak sawdust & Normal & 29.94 & {$[185]$} \\
ZnCl $_{2}$ activated POME sludge & Normal & 22.40 & {$[187]$} \\
Salvadora persica stem ash & Normal & 22.78 & {$[189]$} \\
Activated fly-ash & Normal & 14.28 & {$[190]$} \\
Fly-ash A & Normal & 6.0 & {$[72]$} \\
Coir pith carbon & Normal & 5.87 & {$[194]$} \\
Neem sawdust & Normal & 3.62 & {$[195]$} \\
\hline
\end{tabular}



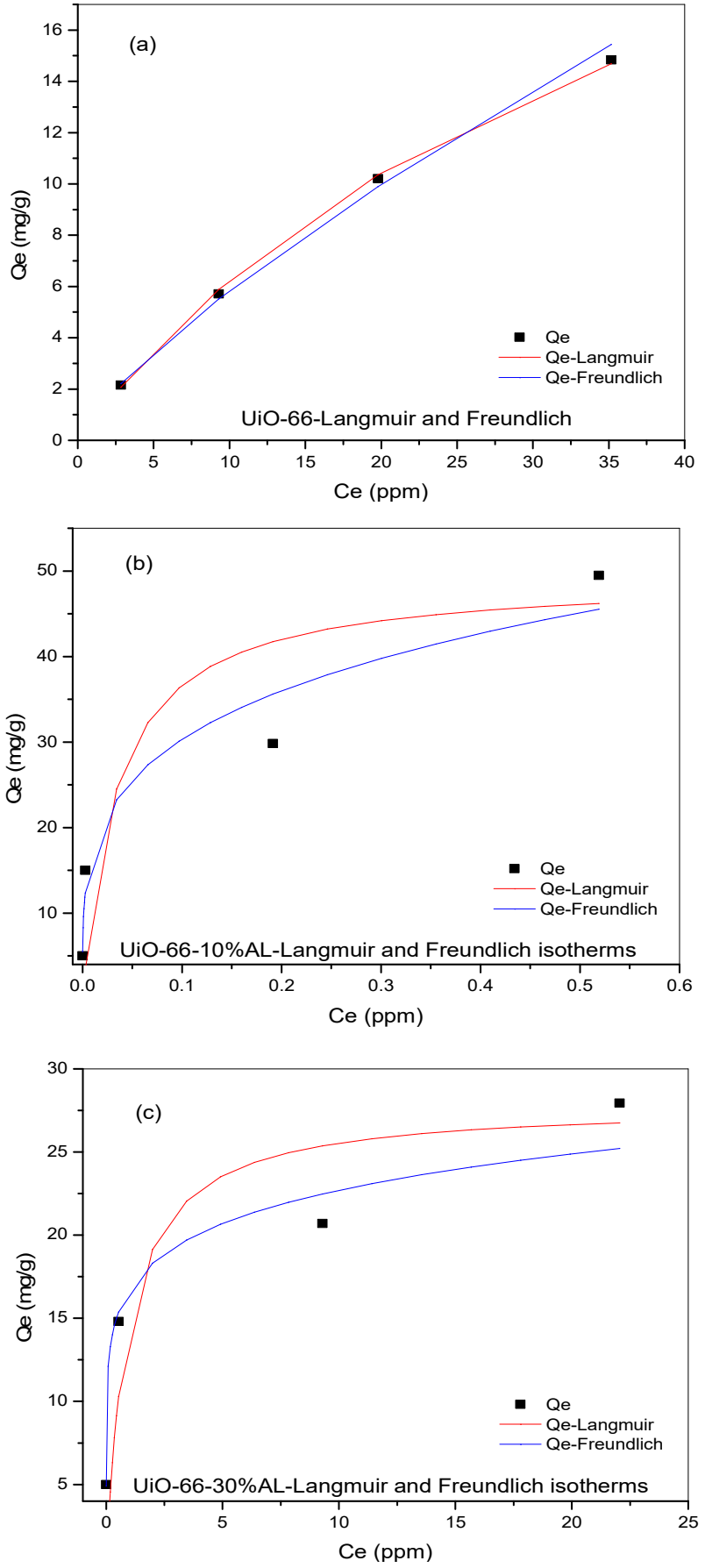

Fig. 5. Fitting of experimental data using Langmuir and Freundlich models of $\mathrm{MB}$ adsorption onto UiO-66 (a), $\mathrm{UiO}$ $-66-10 \% \mathrm{Al}(\mathrm{b})$ and $\mathrm{UiO}-66-30 \% \mathrm{Al}(\mathrm{c})$.

\section{CONCLUSION}

The results of the present examination of the three Zr-MOFs (single-metal and bimetal) show that these MOFs are favourable adsorbents of the basic (cationic) dye MB from aqueous solutions at a wide range of $\mathrm{MB}$ concentrations. The characterisation of $\mathrm{Zr}-\mathrm{MOF}$ reflected the integrity of their structures, the stability of the functional groups on the organic linkers, the suitability of their textural properties and thermal stability. Such characterisation was performed using XRD patterns, FTIR spectrum, $\mathrm{N}_{2}$ adsorption/desorption isotherm and TGA profiles of the UiO-66 samples.
The most efficient adsorbent among the three Ze-MOFs was UiO-66-10\%Al, with the largest pore volume $\left(1.34 \mathrm{cc} . \mathrm{g}^{-1}\right)$ and pore diameter $(2.33 \mathrm{~nm})$, verifying that the addition of up to $10 \% \mathrm{Al}$ enhanced the textural properties of the prototype $\mathrm{Zr}-\mathrm{MOF}$. For all $\mathrm{MB} / \mathrm{MOF}$ systems, high initial concentrations of $\mathrm{MB}$ were found to facilitate adsorption capacity.

It can be concluded that the pseudo first-order model does not fit the experimental data well. While it can be generally applied to the initial period of the first step of the adsorption consistent with reports of most sorption studies in the literature the applicability of pseudo first-order mechanisms are restricted to a limited fraction of the beginning of the contact time [147]. The Elovich and pseudo second-order models showed the highest correlation in all $\mathrm{MOF} / \mathrm{MB}$ systems studied over a longer period of adsorption. Besides, adsorption kinetics obeyed the pseudo second order kinetics model nicely, based on the fact that the highest correlation coefficients $\left(\mathrm{R}^{2}\right)$ were achieved with this model.

Equilibrium data were tested using the Langmuir and Freundlich models, and were found to be best defined by the Freundlich isotherm. The maximum adsorption capacity of the most efficient adsorbent was $49.26 \mathrm{mg} / \mathrm{g}$ for UiO-66$10 \% \mathrm{Al}$. This performance was compared with that of other porous adsorbents in previous studies.

The gained parameters from this study support the design and lay the foundations for establishing a continuous treatment process that removes $\mathrm{MB}$ from wastewater.

\section{AUTHOR INFORMATION}

\section{Corresponding Author}

*Email: naser.alamery@curtin.edu.au

\section{ORCID}

Shaobin Wang : 0000-0002-1751-9162

Shaomin Liu : 0000-0001-5019-5182

\section{REFERENCES}

[1] Wang Shaobin, Boyjoo Y., Choueib A., Zhu Z.H.. Removal of dyes from aqueous solution using fly ash and red mud. Water Research. 2005; 39(1)

[2] Lin Shuang, Song Zhilong, Che Guangbo, Ren Ao, Li Ping, Liu Chunbo, Zhang Jishuang. Adsorption behavior of metal-organic frameworks for methylene blue from aqueous solution. Microporous and Mesoporous Materials. 2014; 193

[3] Aksu Zümriye. Application of biosorption for the removal of organic pollutants: a review. Process Biochemistry. 2005; 40(3-4)

[4] Garg V.K, Kumar Rakesh, Gupta Renuka. Removal of malachite green dye from aqueous solution by adsorption using agro-industry waste: a case study of Prosopis cineraria. Dyes and Pigments. 2004; 62(1)

[5] Chakrabarti T., Subrahmanyam P. V. R., Sundaresan B. B.. Biodegradation of recalcitrant industrial wastes. In: Wise D.L.. Biotreatment systems, Volume II. CRC Press, Inc.: CRC Press, Inc.; 1988.

[6] Clarke E. A., Anliker R.. Organic Dyes and Pigments. Anthropogenic Compounds. The 
Handbook of Environmental Chemistry. Springer: Springer; 1980.

[7] Azo pigment production. 1956.

[8] Pitter P., Chudoba J.. Biodegradability of organic substance in the aquatic environment. Journal of American Chemical Society. 1990.

[9] Young L. Ligninase-catalysed decolorization of synthetic dyes. Water Research. 1997; 31(5)

[10] Lian Lili, Guo Liping, Guo Chunjing. Adsorption of Congo red from aqueous solutions onto Cabentonite. Journal of Hazardous Materials. 2009; 161(1)

[11] Hessel C., Allegre C., Maisseu M., Charbit F., Moulin P.. Guidelines and legislation for dye house effluents. Journal of Environmental Management. 2007; 83(2)

[12] Hema M., Arivoli S.. Comparative study on the adsorption kinetics and thermodynamics of dyes onto acid activated low cost carbon. International Journal of Physical Sciences. 2007; 2(1)

[13] Essawy Amr A., Ali A. El-Hag, Abdel-Mottaleb M.S.A.. Application of novel copolymer-TiO2 membranes for some textile dyes adsorptive removal from aqueous solution and photocatalytic decolorization. Journal of Hazardous Materials. 2008; 157(2-3)

[14] Kumar K. Vasanth, Ramamurthi V., Sivanesan S.. Modeling the mechanism involved during the sorption of methylene blue onto fly ash. Journal of Colloid and Interface Science. 2005; 284(1)

[15] Chiou Ming-Shen, Ho Pang-Yen, Li Hsing-Ya. Adsorption of anionic dyes in acid solutions using chemically cross-linked chitosan beads. Dyes and Pigments. 2004; 60(1)

[16] Fu Yuzhu, Viraraghavan T. Fungal decolorization of dye wastewaters: a review. Bioresource Technology. 2001; 79(3)

[17] Banat Ibrahim M., Nigam Poonam, Singh Datel, Marchant Roger. Microbial decolorization of textiledyecontaining effluents: A review. Bioresource Technology. 1996; 58(3)

[18] Lee Jae-Wook, Choi Seung-Phil, Thiruvenkatachari Ramesh, Shim Wang-Geun, Moon Hee. Evaluation of the performance of adsorption and coagulation processes for the maximum removal of reactive dyes. Dyes and Pigments. 2006; 69(3)

[19] SULAK M, DEMIRBAS E, KOBYA M. Removal of Astrazon Yellow 7GL from aqueous solutions by adsorption onto wheat bran. Bioresource Technology. 2007; 98(13)

[20] Qadeer Riaz. Adsorption behavior of ruthenium ions on activated charcoal from nirtic acid medium. Colloids and Surfaces A: Physicochemical and Engineering Aspects. 2007; 293(1-3)

[21] Pollard S.J.T., Fowler G.D., Sollars C.J., Perry R. Low-cost adsorbents for waste and wastewater treatment: a review. Science of The Total Environment. 1992; 116(1-2)

[22] Valix M., Cheung W.H., McKay G.. Preparation of activated carbon using low temperature carbonisation and physical activation of high ash raw bagasse for acid dye adsorption. Chemosphere. 2004; 56(5)

[23] Namasivayam C., Kavitha D.. Removal of Congo Red from water by adsorption onto activated carbon prepared from coir pith, an agricultural solid waste. Dyes and Pigments. 2002; 54(1)

[24] Namasivayam C., Prabha D., Kumutha M.. Removal of direct red and acid brilliant blue by adsorption on to banana pith. Bioresource Technology. 1998; 64(1)

[25] Tan I.A.W., Ahmad A.L., Hameed B.H.. Preparation of activated carbon from coconut husk: Optimization study on removal of 2,4,6trichlorophenol using response surface methodology. Journal of Hazardous Materials. 2008; 153(1-2)

[26] Juang Ruey-Shin, Wu Feng-Chin, Tseng Ru-Ling. Characterization and use of activated carbons prepared from bagasses for liquid-phase adsorption. Colloids and Surfaces A: Physicochemical and Engineering Aspects. 2002; 201(1-3)

[27] Mohamed Mohamed Mokhtar. Acid dye removal: comparison of surfactant-modified mesoporous FSM-16 with activated carbon derived from rice husk. Journal of Colloid and Interface Science. 2004; 272(1)

[28] Aygün A, Yenisoy-Karakaş S, Duman I. Production of granular activated carbon from fruit stones and nutshells and evaluation of their physical, chemical and adsorption properties. Microporous and Mesoporous Materials. 2003; 66(2-3)

[29] Tseng Ru-Ling, Wu Feng-Chin, Juang Ruey-Shin. Liquid-phase adsorption of dyes and phenols using pinewood-based activated carbons. Carbon. 2003; 41(3)

[30] Malik P.K.. Use of activated carbons prepared from sawdust and rice-husk for adsorption of acid dyes: a case study of Acid Yellow 36. Dyes and Pigments. 2003; 56(3)

[31] Weng Chih-Huang, Lin Yao-Tung, Tzeng Tai-Wei. Removal of methylene blue from aqueous solution by adsorption onto pineapple leaf powder. Journal of Hazardous Materials. 2009; 170(1)

[32] El-Halwany M.M.. Study of adsorption isotherms and kinetic models for Methylene Blue adsorption on activated carbon developed from Egyptian rice hull (Part II). Desalination. 2010; 250(1)

[33] Leechart Piyawan, Nakbanpote Woranan, Thiravetyan Paitip. Application of 'waste' wood-shaving bottom ash for adsorption of azo reactive dye. Journal of Environmental Management. 2009; 90(2)

[34] McKay G., Porter J. F., Prasad G. R.. The Removal of Dye Colours from Aqueous Solutions by Adsorption on Low-cost Materials. Water, Air, and Soil Pollution. 1999; 114

[35] Hameed B.H.. Grass waste: A novel sorbent for the removal of basic dye from aqueous solution. Journal of Hazardous Materials. 2009; 166(1) 
[36] Hameed B.H.. Evaluation of papaya seeds as a novel non-conventional low-cost adsorbent for removal of methylene blue. Journal of Hazardous Materials. 2009; 162(2-3)

[37] Hameed B.H., Mahmoud D.K., Ahmad A.L.. Sorption of basic dye from aqueous solution by pomelo (Citrus grandis) peel in a batch system. Colloids and Surfaces A: Physicochemical and Engineering Aspects. 2008; 316(1-3)

[38] Ponnusami V., Vikram S., Srivastava S.N.. Guava (Psidium guajava) leaf powder: Novel adsorbent for removal of methylene blue from aqueous solutions. Journal of Hazardous Materials. 2008; $152(1)$

[39] Hameed B.H.. Removal of cationic dye from aqueous solution using jackfruit peel as non-conventional low-cost adsorbent. Journal of Hazardous Materials. 2009; 162(1)

[40] Hameed B.H., Mahmoud D.K., Ahmad A.L.. Sorption equilibrium and kinetics of basic dye from aqueous solution using banana stalk waste. Journal of Hazardous Materials. 2008; 158(2-3)

[41] Ofomaja Augustine E.. Sorption dynamics and isotherm studies of methylene blue uptake on to palm kernel fibre. Chemical Engineering Journal. 2007; 126(1)

[42] Gong Renmin, Jin Youbin, Chen Jian, Hu Yun, Sun Jin. Removal of basic dyes from aqueous solution by sorption on phosphoric acid modified rice straw. Dyes and Pigments. 2007; 73(3)

[43] Hameed B.H., El-Khaiary M.I.. Sorption kinetics and isotherm studies of a cationic dye using agricultural waste: Broad bean peels. Journal of Hazardous Materials. 2008; 154(1-3)

[44] Ponnusami V., Gunasekar V., Srivastava S.N.. Kinetics of methylene blue removal from aqueous solution using gulmohar (Delonix regia) plant leaf powder: Multivariate regression analysis. Journal of Hazardous Materials. 2009; 169(1-3)

[45] Aksu Zümriye, Tezer Sevilay. Equilibrium and kinetic modelling of biosorption of Remazol Black B by Rhizopus arrhizus in a batch system: effect of temperature. Process Biochemistry. 2000; 36(5)

[46] Chu H.C, Chen K.M. Reuse of activated sludge biomass: I. Removal of basic dyes from wastewater by biomass. Process Biochemistry. 2002; 37(6)

[47] Fu Yuzhu, Viraraghavan T.. Removal of Congo Red from an aqueous solution by fungus Aspergillus niger. Advances in Environmental Research. 2002; $7(1)$

[48] Aksu Zümriye, Yener Jülide. A comparative adsorption/biosorption study of mono-chlorinated phenols onto various sorbents. Waste Management. 2001; 21(8)

[49] Mou Duen-Gang, Lim Kim Kee, Shen Hwei Ping. Microbial agents for decolorization of dye wastewater. Biotechnology Advances. 1991; 9(4)

[50] $\mathrm{Hu}$ Tai-Lee. Removal of reactive dyes from aqueous solution by different bacterial genera. Water Science and Technology. 1996; 34(10)
[51] Fu Yuzhu, Viraraghavan T. Dye biosorption sites in Aspergillus niger. Bioresource Technology. 2002; $82(2)$

[52] Basibuyuk M., Forster C.F.. An examination of the adsorption characteristics of a basic dye (Maxilon Red BL-N) on to live activated sludge system. Process Biochemistry. 2003; 38(9)

[53] Jacobsen Bo Neergaard, Arvin Erik, Reinders Math. Factors affecting sorption of pentachlorophenol to suspended microbial biomass. Water Research. 1996; 30(1)

[54] Benoit Pierre, Barriuso Enrique, Calvet Raoul. Biosorption characterization of herbicides, 2,4-D and atrazine, and two chlorophenols on fungal mycelium. Chemosphere. 1998; 37(7)

[55] Aksu Z, Akpınar D. Modelling of simultaneous biosorption of phenol and nickel(II) onto dried aerobic activated sludge. Separation and Purification Technology. 2000; 21(1-2)

[56] Aksu Zümriye, Gönen Ferda. Biosorption of phenol by immobilized activated sludge in a continuous packed bed: prediction of breakthrough curves. Process Biochemistry. 2004; 39(5)

[57] Lièvremont Didier, Seigle-murandi Francoise, Benoit -guyod Jean-louis. Removal of PCNB from aqueous solution by a fungal adsorption process. Water Research. 1998; 32(12)

[58] Alpat Sibel Kılınç, Özbayrak Özge, Alpat Şenol, Akçay Hüsamettin. The adsorption kinetics and removal of cationic dye, Toluidine Blue $\mathrm{O}$, from aqueous solution with Turkish zeolite. Journal of Hazardous Materials. 2008; 151(1)

[59] Han Runping, Wang Yi, Zou Weihua, Wang Yuanfeng, Shi Jie. Comparison of linear and nonlinear analysis in estimating the Thomas model parameters for methylene blue adsorption onto natural zeolite in fixed-bed column. Journal of Hazardous Materials. 2007; 145(1-2)

[60] Wang S, Zhu Z. Characterisation and environmental application of an Australian natural zeolite for basic dye removal from aqueous solution. Journal of Hazardous Materials. 2006; 136(3)

[61] Wang Shaobin, Li Huiting, Xu Longya. Application of zeolite MCM-22 for basic dye removal from wastewater. Journal of Colloid and Interface Science. 2006; 295(1)

[62] Li Changxin, Zhong Hong, Wang Shuai, Xue Jianrong, Zhang Zhenyu. Removal of basic dye (methylene blue) from aqueous solution using zeolite synthesized from electrolytic manganese residue. Journal of Industrial and Engineering Chemistry. 2015; 23

[63] Sun Zhi, Li Chunjie, Wu Deyi. Removal of methylene blue from aqueous solution by adsorption onto zeolite synthesized from coal fly ash and its thermal regeneration. Journal of Chemical Technology \& Biotechnology. 2010; 85(6)

[64] Gulnaz O. Sorption of basic dyes from aqueous solution by activated sludge. Journal of Hazardous Materials. 2004; 108(3) 
[65] Gupta V. K., Suhas Suhas, Ali Imran, Saini V. K.. Removal of Rhodamine B, Fast Green, and Methylene Blue from Wastewater Using Red Mud, an Aluminum Industry Waste. Industrial \& Engineering Chemistry Research. 2004; 43(7)

[66] Otero M, Rozada F, Calvo L.F, Garcı冈a A.I, Morán A. Kinetic and equilibrium modelling of the methylene blue removal from solution by adsorbent materials produced from sewage sludges. Biochemical Engineering Journal. 2003; 15(1)

[67] Wang Shaobin, Boyjoo Y., Choueib A.. A comparative study of dye removal using fly ash treated by different methods. Chemosphere. 2005; 60(10)

[68] Wang Shaobin, Ma Qing, Zhu Z.H.. Characteristics of coal fly ash and adsorption application. Fuel. 2008; 87(15-16)

[69] Janos P. Sorption of dyes from aqueous solutions onto fly ash. Water Research. 2003; 37(20)

[70] Lin J.X., Zhan S.L., Fang M.H., Qian X.Q., Yang H.. Adsorption of basic dye from aqueous solution onto fly ash. Journal of Environmental Management. 2008; 87(1)

[71] Sun Deshuai, Zhang Xiaodong, Wu Yude, Liu Xin. Adsorption of anionic dyes from aqueous solution on fly ash. Journal of Hazardous Materials. 2010; 181 (1-3)

[72] Ghosh Dipa, Bhattacharyya Krishna G. Adsorption of methylene blue on kaolinite. Applied Clay Science. 2002; 20(6)

[73] Atun G., Hisarli G., Sheldrick W.S., Muhler M.. Adsorptive removal of methylene blue from colored effluents on fuller's earth. Journal of Colloid and Interface Science. 2003; 261(1)

[74] Hong Song, Wen Cheng, He Jing, Gan Fuxing, Ho Yuh-Shan. Adsorption thermodynamics of Methylene Blue onto bentonite. Journal of Hazardous Materials. 2009; 167(1-3)

[75] Gürses A, Karaca S, Doğar Ç, Bayrak R, Açıkyıldız M, Yalçın M. Determination of adsorptive properties of clay/water system: methylene blue sorption. Journal of Colloid and Interface Science. 2004; 269(2)

[76] Shawabkeh R. Experimental study and modeling of basic dye sorption by diatomaceous clay. Applied Clay Science. 2003; 24(1-2)

[77] Hajjaji M, Alami A, Bouadili A. Removal of methylene blue from aqueous solution by fibrous clay minerals. Journal of Hazardous Materials. 2006; 135 (1-3)

[78] Al-Futaisi Ahmed, Jamrah Ahmad, Al-Hanai Rashid. Aspects of cationic dye molecule adsorption to palygorskite. Desalination. 2007; 214(1-3)

[79] Al-Ghouti M.A., Khraisheh M.A.M., Allen S.J., Ahmad M.N.. The removal of dyes from textile wastewater: a study of the physical characteristics and adsorption mechanisms of diatomaceous earth. Journal of Environmental Management. 2003; 69(3)

[80] Weng Chih-Huang, Pan Yi-Fong. Adsorption of a cationic dye (methylene blue) onto spent activated clay. Journal of Hazardous Materials. 2007; 144(1-2)

[81] Senkal Bahire Filiz, Yavuz Erdem. Preparation of poly (vinyl pyrrolidone) grafted sulfonamide based polystyrene resin and its use for the removal of dye from water. Polymers for Advanced Technologies. 2006; 17(11-12)

[82] Senkal Bahire Filiz, Bildik Fatih, Yavuz Erdem, Sarac Ayfer. Preparation of poly(glycidyl methacrylate) grafted sulfonamide based polystyrene resin with tertiary amine for the removal of dye from water. Reactive and Functional Polymers. 2007; 67(12)

[83] Yu Ying, Zhuang Yuan-Yi, Wang Zhong-Hua, Qiu Ming-Qiang. Adsorption of water-soluble dyes onto modified resin. Chemosphere. 2004; 54(3)

[84] Wawrzkiewicz Monika. Removal of C.I. Basic Blue 3 dye by sorption onto cation exchange resin, functionalized and non-functionalized polymeric sorbents from aqueous solutions and wastewaters. Chemical Engineering Journal. 2013; 217

[85] Kumar K. Yogesh, Muralidhara H.B., Nayaka Y. Arthoba, Balasubramanyam J., Hanumanthappa H.. Low-cost synthesis of metal oxide nanoparticles and their application in adsorption of commercial dye and heavy metal ion in aqueous solution. Powder Technology. 2013; 246

[86] Afkhami Abbas, Moosavi Razieh. Adsorptive removal of Congo red, a carcinogenic textile dye, from aqueous solutions by maghemite nanoparticles. Journal of Hazardous Materials. 2010; 174(1-3)

[87] Haque Enamul, Jun Jong Won, Jhung Sung Hwa. Adsorptive removal of methyl orange and methylene blue from aqueous solution with a metal-organic framework material, iron terephthalate (MOF-235). Journal of Hazardous Materials. 2011; 185(1)

[88] Hasan Zubair, Jhung Sung Hwa. Removal of hazardous organics from water using metal-organic frameworks (MOFs): Plausible mechanisms for selective adsorptions. Journal of Hazardous Materials. 2015; 283

[89] Haque Enamul, Lee Ji Eun, Jang In Tae, Hwang Young Kyu, Chang Jong-San, Jegal Jonggeon, Jhung Sung Hwa. Adsorptive removal of methyl orange from aqueous solution with metal-organic frameworks, porous chromiumbenzenedicarboxylates. Journal of Hazardous Materials. 2010; 181(1-3)

[90] Du Jing-Jing, Yuan Yu-Peng, Sun Jia-Xin, Peng Fu-Min, Jiang Xia, Qiu Ling-Guang, Xie An-Jian, Shen Yu-Hua, Zhu Jun-Fa. New photocatalysts based on MIL-53 metal-organic frameworks for the decolorization of methylene blue dye. Journal of Hazardous Materials. 2011; 190(1-3)

[91] Hameed B, Din A, Ahmad A. Adsorption of methylene blue onto bamboo-based activated carbon: Kinetics and equilibrium studies. Journal of Hazardous Materials. 2007; 141(3) 
[92] Tan I.A.W., Hameed B.H., Ahmad A.L.. Equilibrium and kinetic studies on basic dye adsorption by oil palm fibre activated carbon. Chemical Engineering Journal. 2007; 127(1-3)

[93] Hameed B.H., Ahmad A.L., Latiff K.N.A.. Adsorption of basic dye (methylene blue) onto activated carbon prepared from rattan sawdust. Dyes and Pigments. 2007; 75(1)

[94] Tan I, Ahmad A, Hameed B. Optimization of preparation conditions for activated carbons from coconut husk using response surface methodology. Chemical Engineering Journal. 2008; 137(3)

[95] Li Hailian, Eddaoudi Mohamed, O'Keeffe M., Yaghi O. M.. Design and synthesis of an exceptionally stable and highly porous metal-organic framework. Nature. 1999; 402(6759)

[96] Férey Gérard. Hybrid porous solids: past, present, future. Chem. Soc. Rev.. 2008; 37(1)

[97] Horike Satoshi, Shimomura Satoru, Kitagawa Susumu. Soft porous crystals. Nature Chemistry. 2009; 1(9)

[98] Moghadam Peyman Z., Li Aurelia, Wiggin Seth B., Tao Andi, Maloney Andrew G. P., Wood Peter A., Ward Suzanna C., Fairen-Jimenez David. Development of a Cambridge Structural Database Subset: A Collection of Metal-Organic Frameworks for Past, Present, and Future. Chemistry of Materials. 2017; 29(7)

[99] Kuppler Ryan J., Timmons Daren J., Fang Qian-Rong, Li Jian-Rong, Makal Trevor A., Young Mark D., Yuan Daqiang, Zhao Dan, Zhuang Wenjuan, Zhou Hong-Cai. Potential applications of metal-organic frameworks. Coordination Chemistry Reviews. 2009; 253(23-24)

[100]Li Hailian, Eddaoudi Mohamed, Groy Thomas L., Yaghi O. M.. Establishing Microporosity in Open Metal-Organic Frameworks: Gas Sorption Isotherms for $\mathrm{Zn}(\mathrm{BDC}) \quad$ (BDC = 1,4Benzenedicarboxylate). Journal of the American Chemical Society. 1998; 120(33)

[101]Li Jian-Rong, Sculley Julian, Zhou Hong-Cai. MetalOrganic Frameworks for Separations. Chemical Reviews. $2011 ; 112(2)$

[102]Llewellyn Philip L., Bourrelly Sandrine, Serre Christian, Vimont Alexandre, Daturi Marco, Hamon Lomig, De Weireld Guy, Chang Jong-San, Hong Do-Young, Kyu Hwang Young, Hwa Jhung Sung, Férey Gérard. High Uptakes of $\mathrm{CO} 2$ and $\mathrm{CH} 4$ in Mesoporous Metal-Organic Frameworks MIL-100 and MIL-101. Langmuir. 2008; 24(14)

[103]Biradha Kumar, Ramanan Arunachalam, Vittal Jagadese J.. Coordination Polymers Versus Metal-Organic Frameworks. Crystal Growth \& Design. 2009; 9(7)

[104]Yaghi Omar. Keynote Speaker: Dr. Omar Yaghi. Chemical and Biological Defense Science and Technology (CBD S\&T) Conference.

[105]Yaghi Omar M., O'Keeffe Michael, Ockwig Nathan W., Chae Hee K., Eddaoudi Mohamed, Kim Jaheon. Reticular synthesis and the design of new materials. Nature. 2003; 423(6941)

[106] O’Keeffe Michael, Peskov Maxim A., Ramsden Stuart J., Yaghi Omar M.. The Reticular Chemistry Structure Resource (RCSR) Database of, and Symbols for, Crystal Nets. Accounts of Chemical Research. 2008; 41(12)

[107] Ockwig Nathan W., Delgado-Friedrichs Olaf, O'Keeffe Michael, Yaghi Omar M.. Reticular Chemistry: Occurrence and Taxonomy of Nets and Grammar for the Design of Frameworks. Accounts of Chemical Research. 2005; 38(3)

[108]Furukawa Hiroyasu, Cordova Kyle E., O’Keeffe Michael, Yaghi Omar M.. The Chemistry and Applications of Metal-Organic Frameworks. Science. 2013; 341(6149)

[109]Eddaoudi M.. Systematic Design of Pore Size and Functionality in Isoreticular MOFs and Their Application in Methane Storage. Science. 2002; 295 (5554)

[110]Ke Fei, Yuan Yu-Peng, Qiu Ling-Guang, Shen Yu-Hua, Xie An-Jian, Zhu Jun-Fa, Tian Xing-You, Zhang Li-De. Facile fabrication of magnetic metal-organic framework nanocomposites for potential targeted drug delivery. Journal of Materials Chemistry. 2011; 21(11)

[111]Dai Wei, Zhuang H.-T., Lu X.-Q., Han M.-M., Zheng Y.. Adsorptive separation of thiophene derivatives via metal organic framework material MOF-5. Journal of Fuel Chemistry and Technology. 2010; 38(5)

[112] Chen Chen, Zhang Meng, Guan Qingxin, Li Wei. Kinetic and thermodynamic studies on the adsorption of xylenol orange onto MIL-101 (Cr). Chemical Engineering Journal. 2012; 183

[113] Ho Y.S, McKay G. Pseudo-second order model for sorption processes. Process Biochemistry. 1999; 34(5)

[114]Lagergren S.. About the Theory of so Called Adsorption of Soluble Substances. Sven. Vetenskapsakad. Handingarl. 1898; 24

[115]Weber Walter J., Morris J. Carrell. Kinetics of Adsorption on Carbon from Solution. Journal of the Sanitary Engineering Division. 1963; 89(2)

[116]Langmuir Irving. The Constitution and Fundamental Properties of Solids and Liquids. II. Liquids. Journal of the American Chemical Society. 1917; 39(9)

[117]Freundlich Herbert. Über die Adsorption in Lösungen. Zeitschrift für Physikalische Chemie. 1907; 57U(1)

[118] Hameed B.H., Rahman A.A.. Removal of phenol from aqueous solutions by adsorption onto activated carbon prepared from biomass material. Journal of Hazardous Materials. 2008; 160(2-3)

[119]Hameed B.H.. Spent tea leaves: A new non-conventional and low-cost adsorbent for removal of basic dye from aqueous solutions. Journal of Hazardous Materials. 2009; 161(2-3)

[120]Lagergreen S.. Zur Theorie der sogenannten Adsorption gelöster Stoffe. Zeitschrift für Chemie und Industrie der Kolloide. 1907; 2(1)

[121]Low M. J. D.. Kinetics of Chemisorption of Gases on 
Solids.. Chemical Reviews. 1960; 60(3)

[122]Chien S. H., Clayton W. R.. Application of Elovich Equation to the Kinetics of Phosphate Release and Sorption in Soils. Soil Science Society of America Journal. 1980; 44(2)

[123]Kushwaha Jai Prakash, Srivastava Vimal Chandra, Mall Indra Deo. Treatment of dairy wastewater by commercial activated carbon and bagasse fly ash: Parametric, kinetic and equilibrium modelling, disposal studies. Bioresource Technology. 2010; 101 (10)

[124]Langmuir Irving. The Constitution and Fundamental Properties of Solids and Liquids. Part I. Solids. Journal of the American Chemical Society. 1916; 38(11)

[125]Hall K. R., Eagleton L. C., Acrivos Andreas, Vermeulen Theodore. Pore- and Solid-Diffusion Kinetics in Fixed-Bed Adsorption under ConstantPattern Conditions. Industrial \& Engineering Chemistry Fundamentals. 1966; 5(2)

[126] Gupta G.S., Prasad G., Panday K.K., Singh V.N.. Removal of chrome dye from aqueous solutions by fly ash. Water, Air, and Soil Pollution. 1988; 37(1-2)

[127] Namasivayam C., Sumithra S.. Removal of direct red $12 \mathrm{~B}$ and methylene blue from water by adsorption onto $\mathrm{Fe}$ (III)/Cr (III) hydroxide, an industrial solid waste. Journal of Environmental Management. 2005; 74(3)

[128]Di Marino Antonio, Mendicuti Francisco. Thermodynamics of Complexation of Dimethyl Esters of Tere-, Iso-, and Phthalic Acids with $\alpha$ - and $\beta$ -Cyclodextrins. Applied Spectroscopy. 2004; 58(7)

[129]Dhumal Nilesh R., Singh Manish P., Anderson James A., Kiefer Johannes, Kim Hyung J.. Molecular Interactions of a Cu-Based Metal-Organic Framework with a Confined Imidazolium-Based Ionic Liquid: A Combined Density Functional Theory and Experimental Vibrational Spectroscopy Study. The Journal of Physical Chemistry C. 2016; $120(6)$

[130]Coates John . Interpretation of Infrared Spectra, A Practical Approach. Infrared Spectroscopy. 2006.

[131] Aroke U O , Abdulkarim A, Ogubunka R O . Fouriertransform Infrared Characterization of Kaolin, Granite, Bentonite and Barite. ATBU Journal of Environmental Technology. 2013; 6(1)

[132] Schlichte Klaus, Kratzke Tobias, Kaskel Stefan. Improved synthesis, thermal stability and catalytic properties of the metal-organic framework compound $\mathrm{Cu} 3(\mathrm{BTC}) 2$. Microporous and Mesoporous Materials. 2004; 73(1-2)

[133]Aljeboree Aseel M., Alshirifi Abbas N., Alkaim Ayad F.. Kinetics and equilibrium study for the adsorption of textile dyes on coconut shell activated carbon. Arabian Journal of Chemistry. 2017; 10

[134]de Menezes Eliana W., Lima Eder C., Royer Betina, de Souza Felipe E., dos Santos Bruna D., Gregório José R., Costa Tania M.H., Gushikem Yoshitaka, Benvenutti Edilson V.. Ionic silica based hybrid material containing the pyridinium group used as an adsorbent for textile dye. Journal of Colloid and Interface Science. 2012; 378(1)

[135] Ho Yuh-Shan. Second-order kinetic model for the sorption of cadmium onto tree fern: A comparison of linear and non-linear methods. Water Research. 2006; 40(1)

[136] Ho Yuh-Shan. Absorption of heavy metals from waste streams by peat. 1995 .

[137] Ho Y.S, McKay G. A kinetic study of dye sorption by biosorbent waste product pith. Resources, Conservation and Recycling. 1999; 25(3-4)

[138]Badmus M A O, Audu T. O. K. , Anyata B U . Removal of Lead Ion from Industrial Wastewaters by Activated Carbon Prepared from Periwinkle Shells (Typanotonus fuscatus). Turkish Journal of Engineering and Environmental Sciences. 2007; 31(4)

[139]Ho Y.S., McKay G.. A Comparison of Chemisorption Kinetic Models Applied to Pollutant Removal on Various Sorbents. Process Safety and Environmental Protection. 1998; 76(4)

[140]Namasivayam C., Kanchana N.. Waste banana pith as adsorbent for color removal from wastewaters. Chemosphere. 1992; 25(11)

[141] Namasivayam C., Yamuna R. T.. Removal of congo red from aqueous solutions by biogas waste slurry. Journal of Chemical Technology \& Biotechnology. 2007; 53(2)

[142] Namasivayam C., Yamuna R. T.. Removal of Rhodamine-B by biogas waste slurry from aqueous solution. Water, Air, \& Soil Pollution. 1992; 65(1-2)

[143] Yamuna R. T., Namasivayam C.. Color removal from aqueous solution by biogas residual slurry. Toxicological \& Environmental Chemistry. 1993; 38(3-4)

[144] Namasivayam C., Periasamy K.. Bicarbonate-treated peanut hull carbon for mercury (II) removal from aqueous solution. Water Research. 1993; 27(11)

[145] Namasivayam C., Ranganathan K.. Waste Fe(III)/Cr (III) hydroxide as adsorbent for the removal of $\mathrm{Cr}$ (VI) from aqueous solution and chromium plating industry wastewater. Environmental Pollution. 1993; $82(3)$

[146] Namasivayam Chinnaiya, Thamaraiselvi Kaliannan, Yamuna Rangaiya T.. Removal of paraquat by adsorption on 'waste' $\mathrm{Fe}$ (III)/Cr(III) hydroxide: Adsorption rates and equilibrium studies. Pesticide Science. 1994; 41(1)

[147] Singh Binay K., Rawat Narendra S.. Comparative sorption kinetic studies of phenolic compounds on fly ash and impregnated fly ash. Journal of Chemical Technology AND Biotechnology. 1994; 61(1)

[148]Lee C. K., Low K. S., Chow S. W.. Chrome Sludge as an Adsorbent for Colour Removal. Environmental Technology. 1996; 17(9)

[149]Lee C.K., Low K.S., Kek K.L.. Removal of chromium from aqueous solution. Bioresource Technology. 1995; 54(2)

[150]Low K.S., Lee C.K., Tan K.K.. Biosorption of basic dyes by water hyacinth roots. Bioresource 
Technology. 1995; 52(1)

[151]Biosorption of cationic dyes by dead macro fungus fomitopsis carnea: batch studies. Water Science and Technology. 1996; 34(10)

[152] Namasivayam C., Muniasamy N., Gayatri K., Rani M., Ranganathan K.. Removal of dyes from aqueous solutions by cellulosic waste orange peel. Bioresource Technology. 1996; 57(1)

[153]Kilic Murat, Apaydin-Varol Esin, Pütün Ayşe E.. Adsorptive removal of phenol from aqueous solutions on activated carbon prepared from tobacco residues: Equilibrium, kinetics and thermodynamics. Journal of Hazardous Materials. 2011; 189(1-2)

[154]Shi Yun, Kong Xiangzhen, Zhang Caimeng, Chen Yeming, Hua Yufei. Adsorption of soy isoflavones by activated carbon: Kinetics, thermodynamics and influence of soy oligosaccharides. Chemical Engineering Journal. 2013; 215-216

[155] Shahul Hameed K., Muthirulan P., Meenakshi Sundaram M.. Adsorption of chromotrope dye onto activated carbons obtained from the seeds of various plants: Equilibrium and kinetics studies. Arabian Journal of Chemistry. 2017; 10

[156] Malik R., Ramteke D.S., Wate S.R.. Adsorption of malachite green on groundnut shell waste based powdered activated carbon. Waste Management. 2007; 27(9)

[157] Yener Julide, Kopac Turkan, Dogu Gulsen, Dogu Timur. Adsorption of Basic Yellow 28 from aqueous solutions with clinoptilolite and amberlite. Journal of Colloid and Interface Science. 2006; 294(2)

[158] Hameed B, Daud F. Adsorption studies of basic dye on activated carbon derived from agricultural waste: Hevea brasiliensis seed coat. Chemical Engineering Journal. 2008; 139(1)

[159]Allen S.J., McKay G., Khader K.Y.H.. Intraparticle diffusion of a basic dye during adsorption onto sphagnum peat. Environmental Pollution. 1989; $56(1)$

[160]Mohanty Kaustubha, Das D., Biswas M.N.. Adsorption of phenol from aqueous solutions using activated carbons prepared from Tectona grandis sawdust by $\mathrm{ZnCl} 2$ activation. Chemical Engineering Journal. 2005; 115(1-2)

[161] Mohanty Kaustubha , Jha Mousam , Meikap B. C., Biswas M. N. . Preparation and Characterization of Activated Carbons from Terminalia Arjuna Nut with Zinc Chloride Activation for the Removal of Phenol from Wastewater. Industrial and Engineering Chemistry Research. 2005; 44(11)

[162] Panday K. K., Prasad G., Singh V. N.. Mixed adsorbents for $\mathrm{Cu}(\mathrm{II})$ removal from aqueous solutions. Environmental Technology Letters. 1986; 7 (1-12)

[163] Mohanty Kaustubha, Jha Mousam, Meikap B.C., Biswas M.N.. Removal of chromium (VI) from dilute aqueous solutions by activated carbon developed from Terminalia arjuna nuts activated with zinc chloride. Chemical Engineering Science. 2005; 60(11)

[164] Poots V. J. P. , McKay G. , Healy J. J. . Removal of
Basic Dye from Effluent Using Wood as an Adsorbent. Water Pollution Control Federation. 1978; 50(5)

[165] Marrakchi F., Auta M., Khanday W.A., Hameed B.H.. High-surface-area and nitrogen-rich mesoporous carbon material from fishery waste for effective adsorption of methylene blue. Powder Technology. 2017; 321

[166] Islam Md. Azharul, Ahmed M.J., Khanday W.A., Asif M., Hameed B.H.. Mesoporous activated coconut shell-derived hydrochar prepared via hydrothermal carbonization- $\mathrm{NaOH}$ activation for methylene blue adsorption. Journal of Environmental Management. 2017; 203

[167] Ghosh Rakesh Kumar, Reddy D. Damodar. Tobacco Stem Ash as an Adsorbent for Removal of Methylene Blue from Aqueous Solution: Equilibrium, Kinetics, and Mechanism of Adsorption. Water, Air, \& Soil Pollution. 2013; 224(6)

[168]Ferrero F.. Dye removal by low cost adsorbents: Hazelnut shells in comparison with wood sawdust. Journal of Hazardous Materials. 2007; 142 $(1-2)$

[169] Sapawe N., Jalil A.A., Triwahyono S., Shah M.I.A., Jusoh R., Salleh N.F.M., Hameed B.H., Karim A.H.. Cost-effective microwave rapid synthesis of zeolite $\mathrm{NaA}$ for removal of methylene blue. Chemical Engineering Journal. 2013; 229

[170]Edris Bazrafshan, Ferdos Kord Mostafapour, Mohammad Ali Zazouli. Methylene blue (cationic dye) adsorption into Salvadora persica stems ash. 2012; 11(101)

[171]Banerjee Sushmita, Sharma Gopesh C., Chattopadhyaya M.C., Sharma Yogesh Chandra. Kinetic and equilibrium modeling for the adsorptive removal of methylene blue from aqueous solutions on of activated fly ash (AFSH). Journal of Environmental Chemical Engineering. 2014; 2(3)

[172] Kavitha D, Namasivayam C. Experimental and kinetic studies on methylene blue adsorption by coir pith carbon. Bioresource Technology. 2007; 98(1)

[173] Khattri S. D., Singh M. K.. Colour Removal from Synthetic Dye Wastewater Using a Bioadsorbent. 2000; 120

This article is licensed under a Creative Commons Attriution 4.0 International License. 